Journal of Social Sciences (COES\&RJ-JSS)

ISSN (E): 2305-9249 ISSN (P): 2305-9494

Publisher: Centre of Excellence for Scientific \& Research Journalism, COES\&RJ LLC

Online Publication Date: $1^{\text {st }}$ January 2021

Online Issue: Volume 10, Number 1, January 2021

https://doi.org/10.25255/jss.2021.10.1.119.138

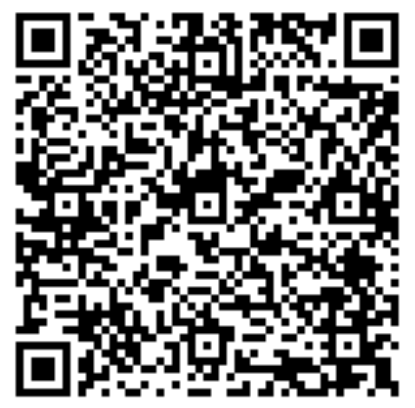

\title{
Liability limits of transport commission agent
}

\author{
Dr. Mohammad Battah
}

http://orcid.org/0000-0002-2410-3966

\begin{abstract}
:
Considering the importance of transport commission agent's work and through the examination of transport commission agent's liability, the intensity and burden of transport commission agent's liability is shown. The legal nature of a transport commission agent's obligation is an obligation to achieve a result, thus he usually has to contract out of liability, either through the legal limits of liability where the law established the legal exemptions that the transport commission agent would benefit from, as well as the agreement limits of liability through the cases in which the law allowed the transport commission agent to establish a condition under the agreement exempts him from liability or specify his damage liability.
\end{abstract}

Since the law prohibited the transport commission agent from establishing any condition that exempted him from liability in the cases of damage and injury, thus he is bound by compensating his agent fully for the occurring damages, except the cases in which the transport commission agent establishes a condition to limit his liability within the limits permitted by the law.

Lastly, the development and importance of the transport commission agent's trade and profession and its resulting legal conflicts and problems are the reason behind conducting this study in order to identify the liability limits of the transport commission agent.

Keywords:

Liability limits of transport commission agent, fraud, Gross fault, Force majeure

This work is licensed under a Creative Commons Attribution 4.0 International License. 


\section{Citation:}

Battah, Mohammad (2021); Liability limits of transport commission agent; Journal of Social Sciences (COES\&RJ-JSS), Vol.10, No.1, pp:119-138; https://doi.org/10.25255/jss.2021.10.1.119.138.

\section{حدود مسؤولية الوكيل بالعمولة للنقل

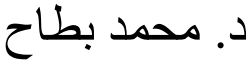 \\ استاذ مساعد \\ جامعة عمان العربية ماعنية \\ m.batah@aau.edu.jo}

نظر اً لأهميَّة عملِ الوكيلِ بالعمولةِ للنَّقلِ ، ومن خلال در اسة مسؤولية الوكيل بالعمولة

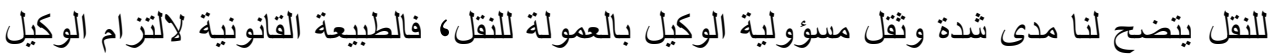

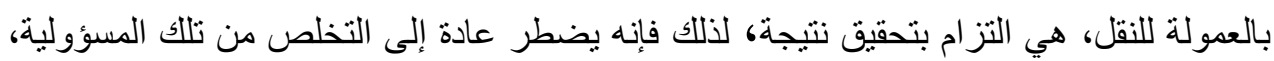

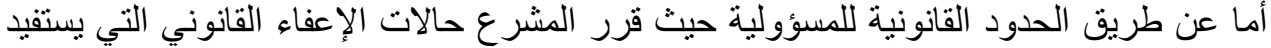

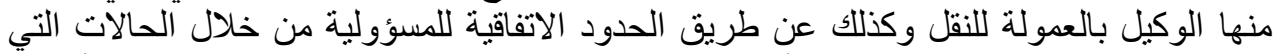

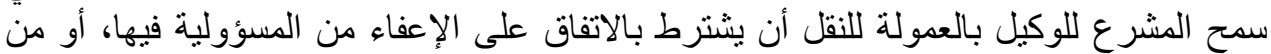

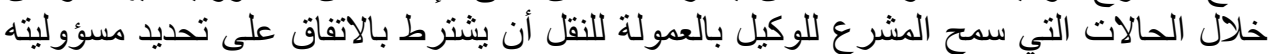
عن الضرر فيها.

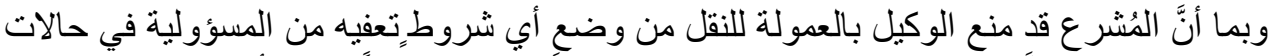

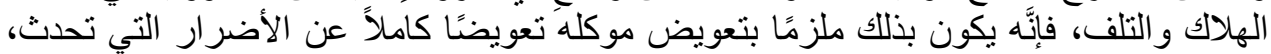

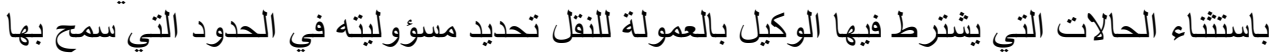
و أخيراً فإنَّ التَّطورَ السَّائد في التجارة ومهنة الوكيل بالعمولة للنقل و أهمية هذه المهنة وما التها القانون.

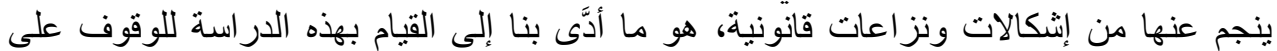

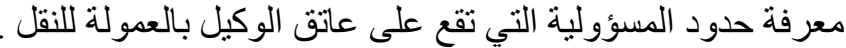

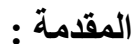

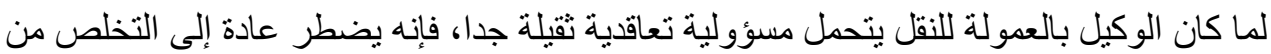

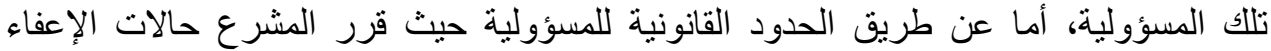

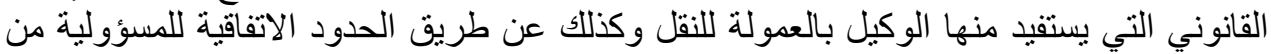

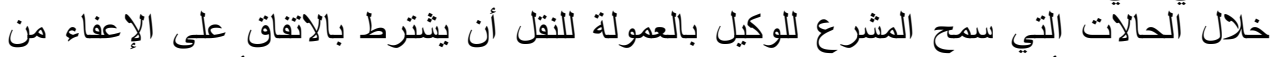

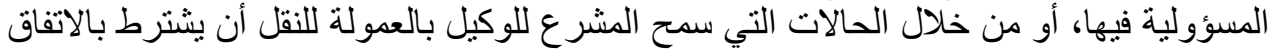

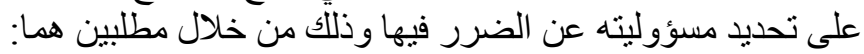

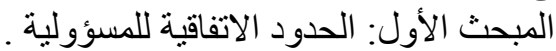

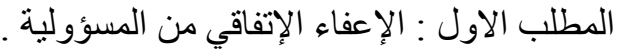

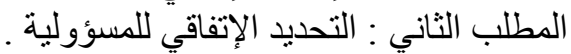

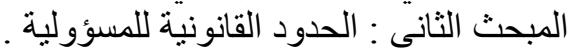

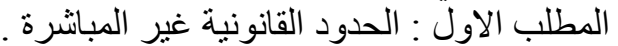

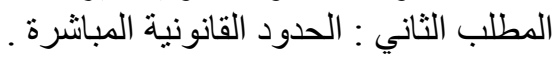


مشكلة الدر اسة:

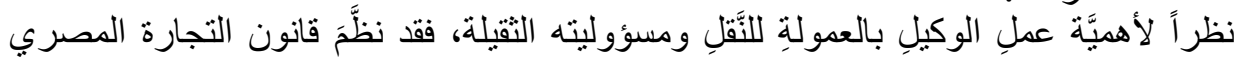

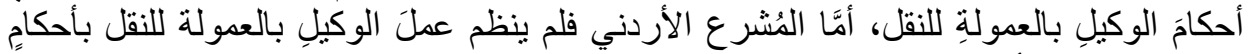

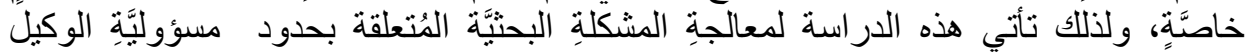

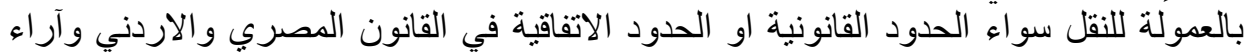
الفقهاء وموقف القضاء.

عناصر مشكلة الدر اسة (أسئلة الدر اسة):

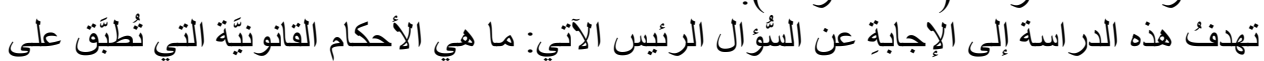

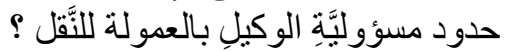
وينبثق عنه الأسئلة الفر عيَّة الآتية:

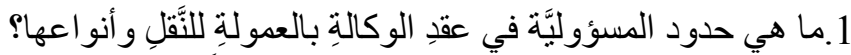

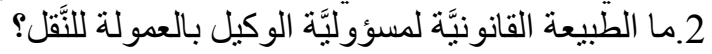

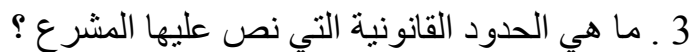

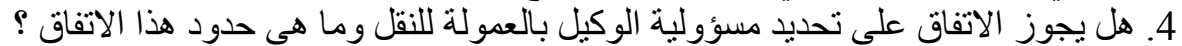

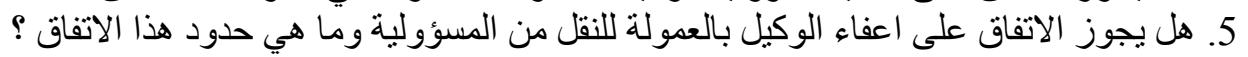
6. هل يستفيد الوكيل بالعمولة للنقل من تحديد الناقل بالقل مسؤوليته ؟

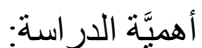

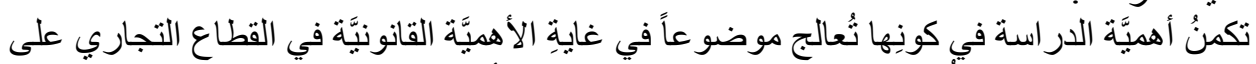

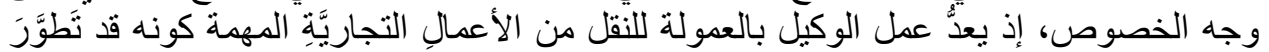

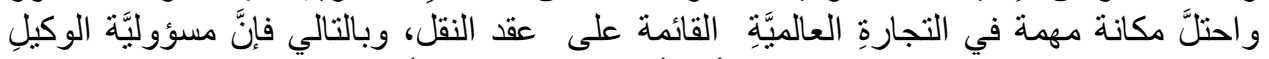

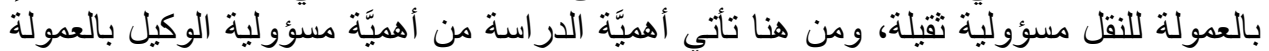

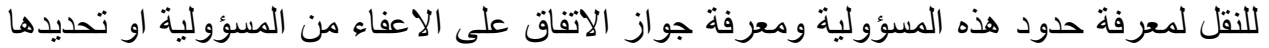

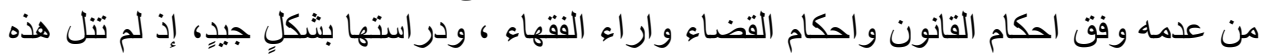

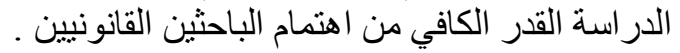

ويسعى الباحث من خلال هذه الدر اسة إلى:

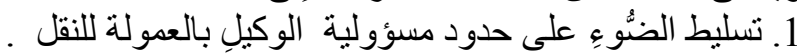

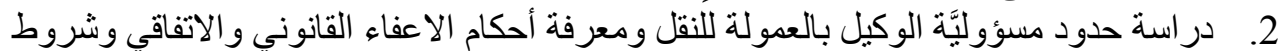

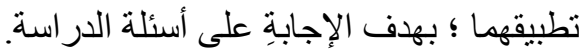

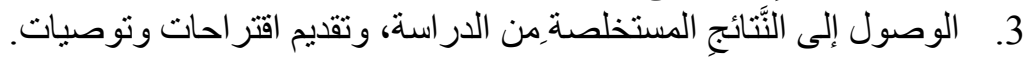

$$
\text { محددات الدراسة: }
$$

المحدد الموضوعي: تقتصر هذه الدراسة على حدود مسؤولية الوكيل بالعمولة للنقل

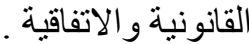
المحدد المكاني: تتحد هذه الدراسة في حدود مسؤولية الوكيل بالعمولة للنقل وشروط تطبيقها في

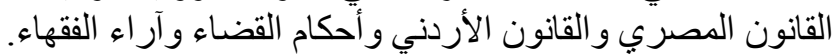

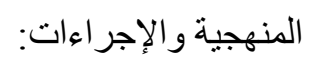

تستخدمُ هذهِ الدر اسة المنهجَ الوصفيَّ التَّحليليَّ لملاعَمته للارِ اسات القانونيَّة، إذ يتم البحث المعمق 


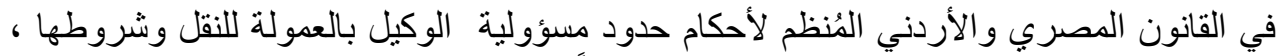

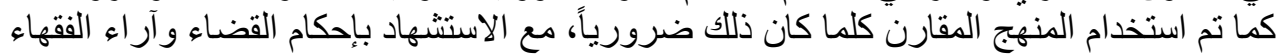

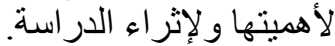

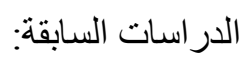

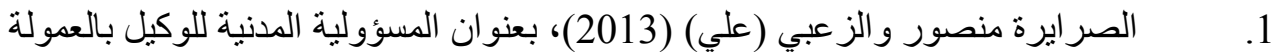
للنقل "در اسة مقارنة بين القانونين الأردني والمغربي، مجلة المنارة للبحوث و والدر اسات، مجلد 19 العدد 1. تناولت في هذه الدراسة موضوع المسؤولية المدنبة للوكيل بالعمولة للنقل كدراسة مقارنة بين

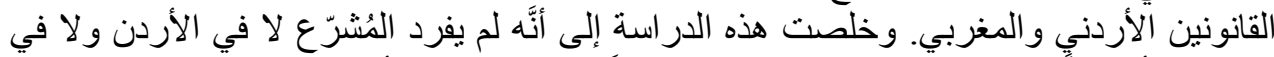

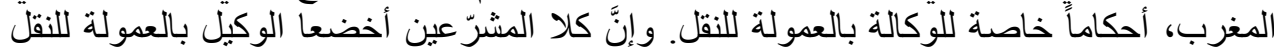

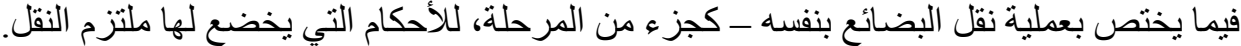

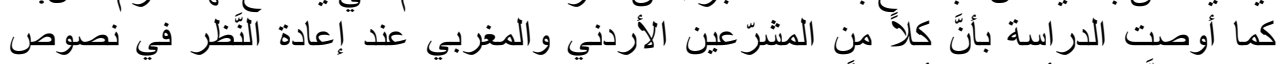

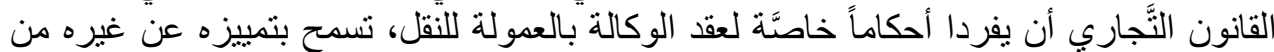

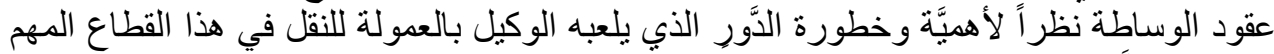
في الحياةِ التَّجاريَّةِ.

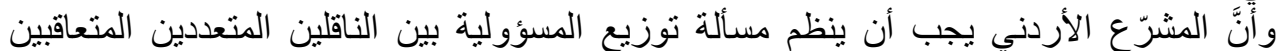

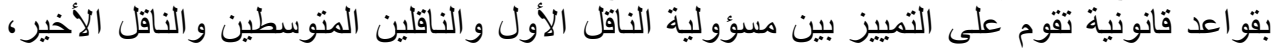

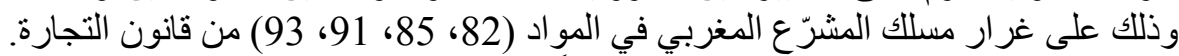

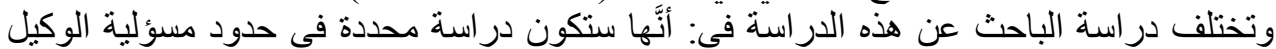

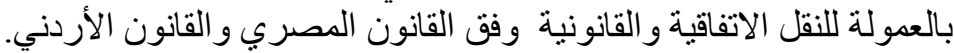

\section{2. د. الفليح هانسي هليل هطيلان (2017), ضمانات طرفي عقل الوكالة بالعمولية في القانون الأربنسي (دراستة مقارنيـة).}

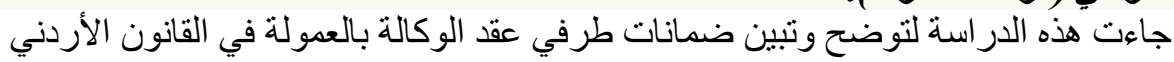

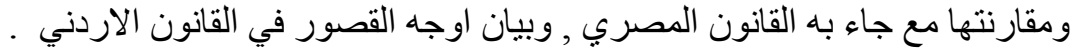

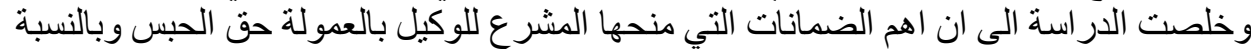

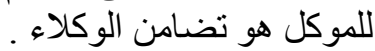

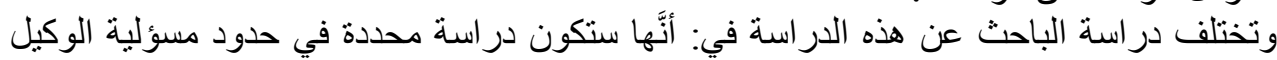

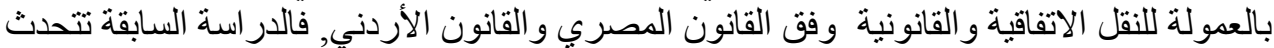

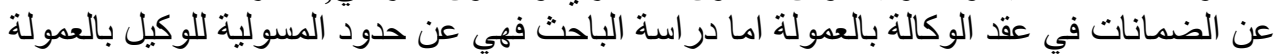
للنقل .

3.أبو طير مروان عبد الله (1996) ، الآثار الناجمة عن عقد الوكالة بالعمولة في القانون الأردني ، رسالة ماجستير ، الجامعة الأردنية .

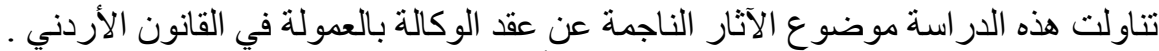

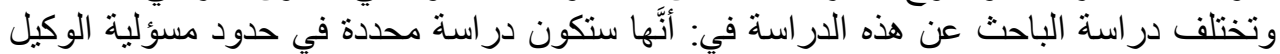
بالعمولة للنقل الاتفاقية والقانونية وفن القانون الانون المصري و القانون الأردني .

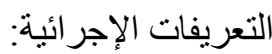
حدود مسؤولية الوكيل بالعمولة للنقل: الحدود القانونية التي نص عليها المشرع و الحدود الاتفاقية التي يجوز الاتفاق عليها . 


\section{Liability limits of transport commission agent}

الغش : يقصد بالغش في مواد النقل كل فعل أو امتناع يقع من الناقل أو من تابعيه بقصد إحداث

الخطأ الجسيم : يقصد بالخطأ الجسيم كل فعل أو امتناع يقع من الناقل أو من تابعيه برعونة مقرونة

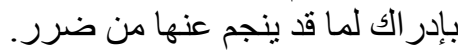

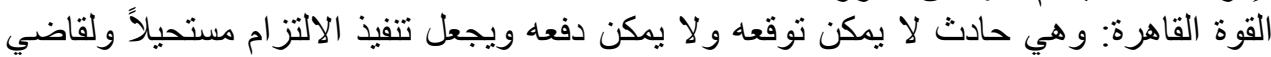

الموضوع السلطة التقديرية في اعتبار الواقعة قوة قاهرة أو لون عدم اعتبار ها.

\section{المبحث الأول \\ الحدود الاتفاقية للمسؤولية}

$$
\text { تمهيد وتقسيح : }
$$

سمح المشرع للوكيل بالعمولة للنقل أن يشترط بالاتفاق مع الموكل على إعفائه من المسؤولية في الإني

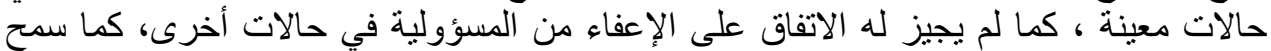

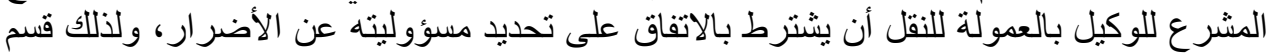

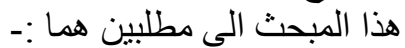
المطلب الاول : الإعفاء الاتفاقي من المسؤولية : الإقاء

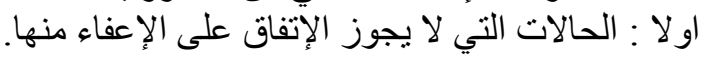

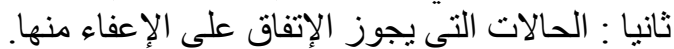

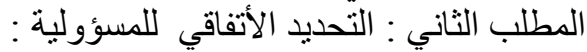

$$
\text { الإعفاء الاتفاقي من المسؤولية }
$$

$$
\text { اولا : الحالات التي لا يجوز الاتفاق على الإعفاء منها :- }
$$

وفق قانون التجارة المصري القديم كان المشرع يسمح للوكيل بالعمولة للنقل الاتفاق مع موكله على الإنى

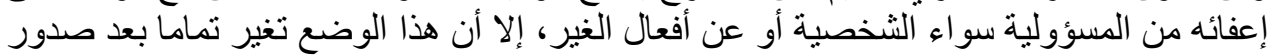

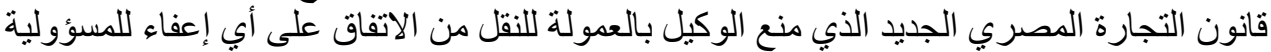

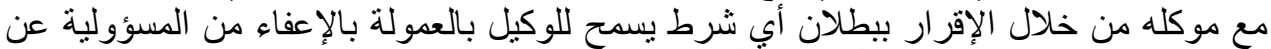

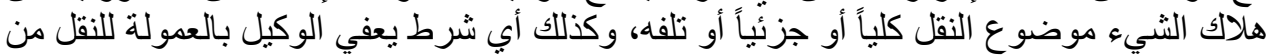

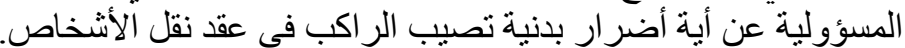

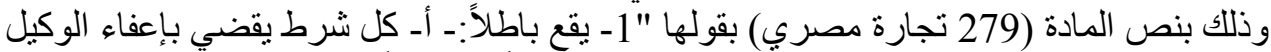

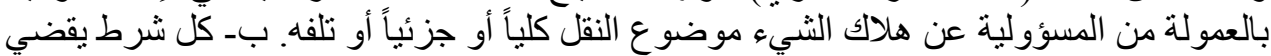

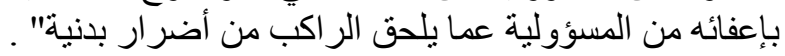
وكذلك قرر المشرع المصري المولي حالتان محددتان يعتبران في حكم الإعفاء من المسؤولية، أي أنهما

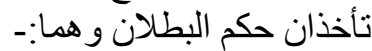

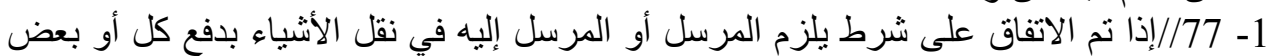

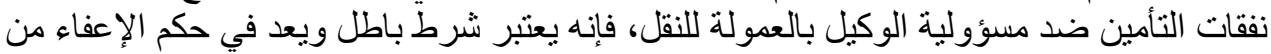

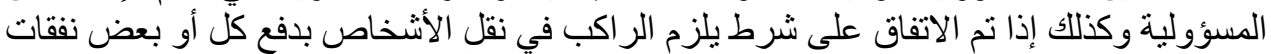

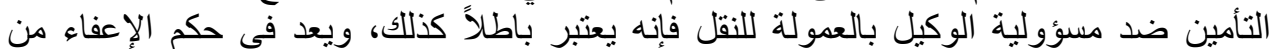

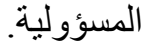

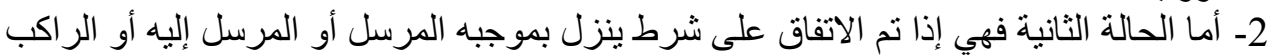

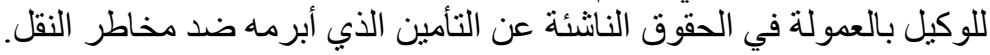




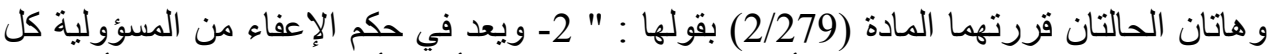

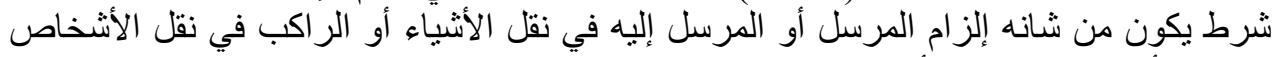

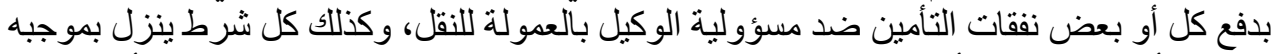

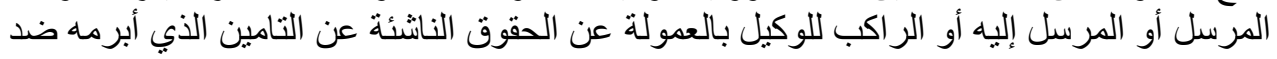

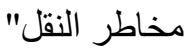

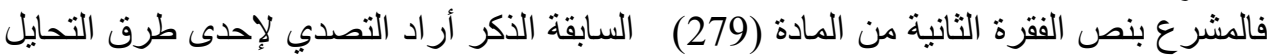

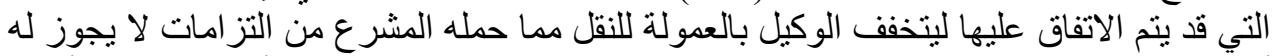

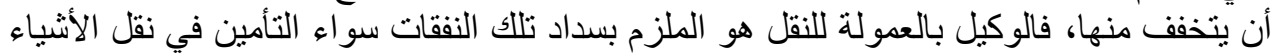

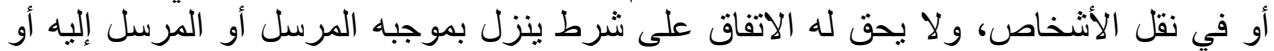

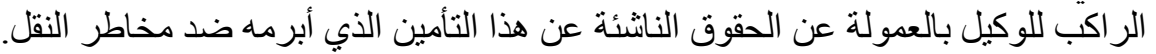

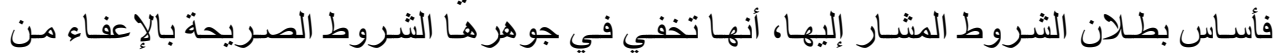

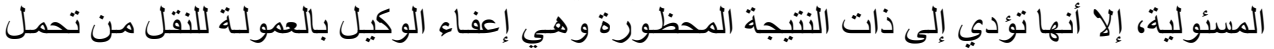

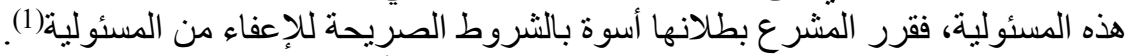

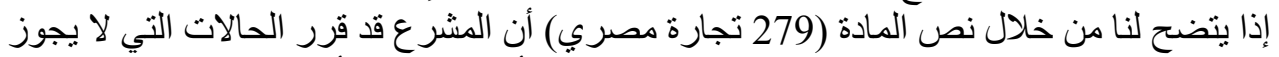

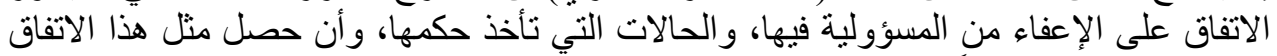

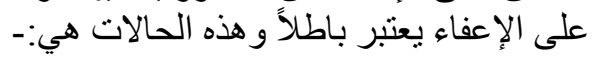

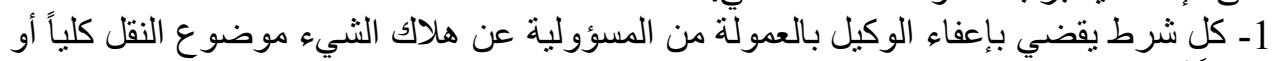
جزئياً أو تلفه.

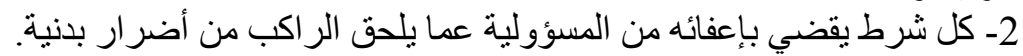

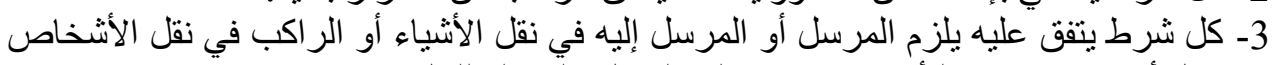

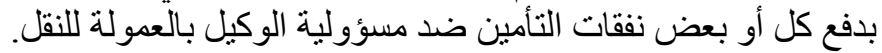

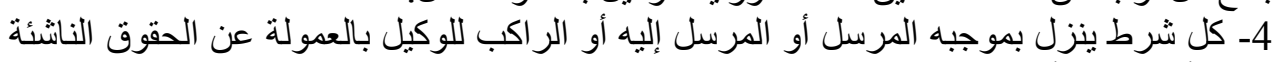

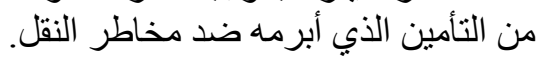

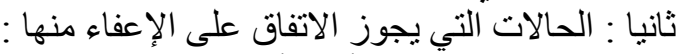

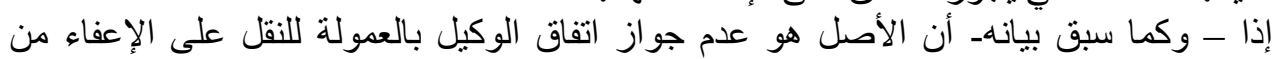

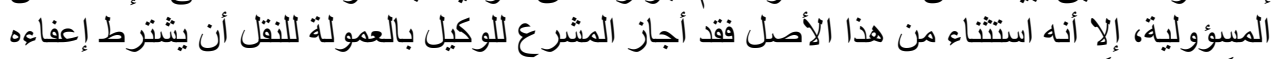

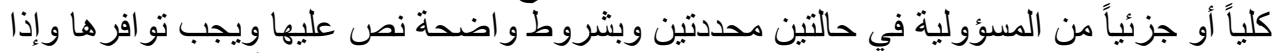

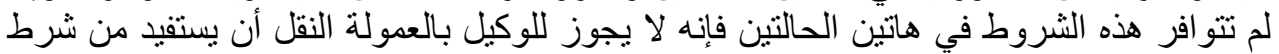
الإعفاء المتفق عليه ويعتبر كأن لم يكن. 1 و هاتان الحالتان هما:

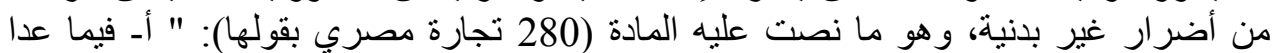

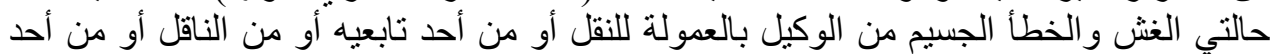

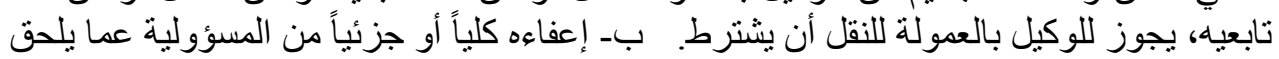

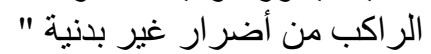

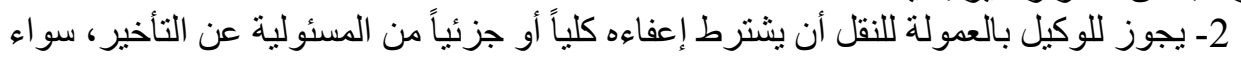

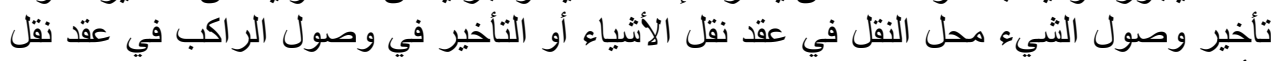
الأشخاص، و هو ماً نصت عليه المادة (280 تجارة مصري) بقولها: " 1- فيما عداء الألتي الغش

(1) د. سميحة القليوبي: الوسيط في شرح قانون التجارة المصري، 2007، ص595. 


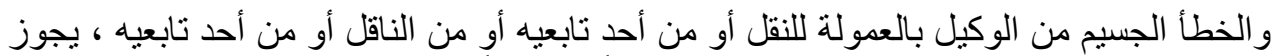

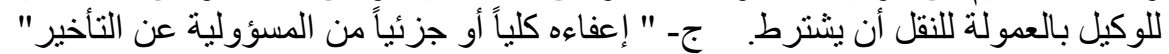

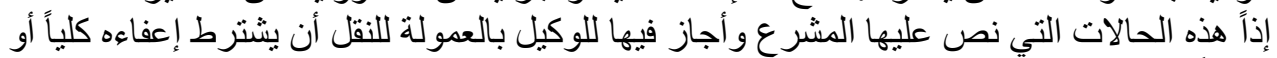

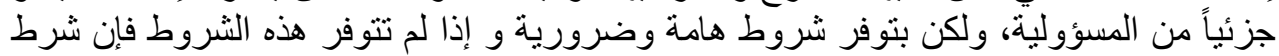

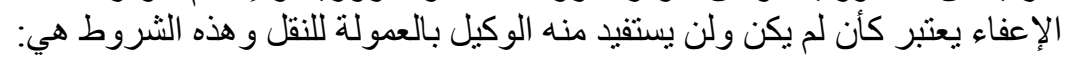

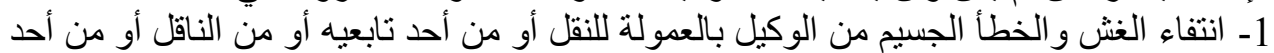

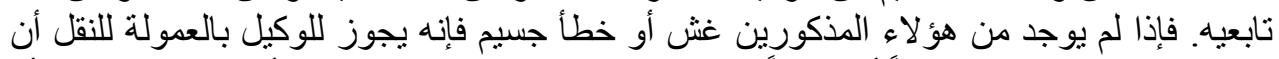

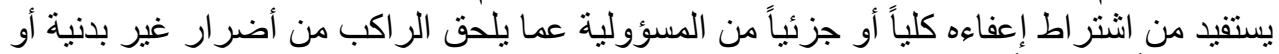

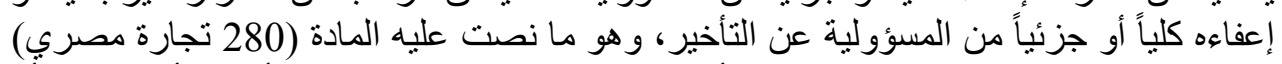

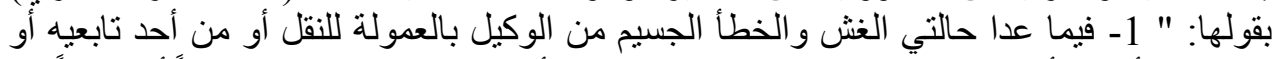

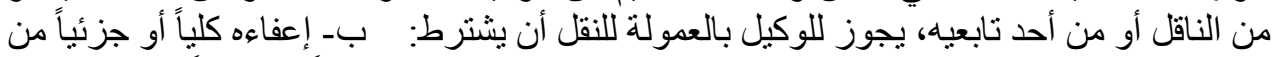

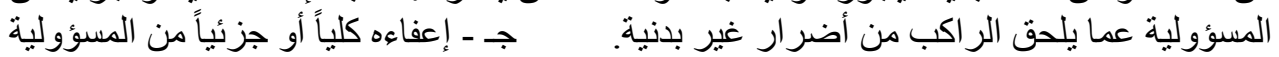

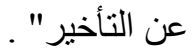

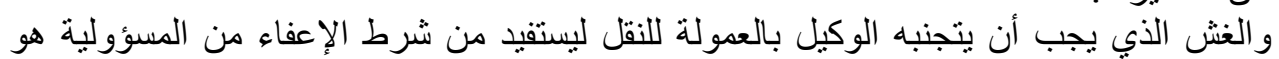

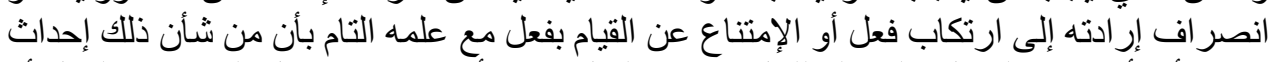

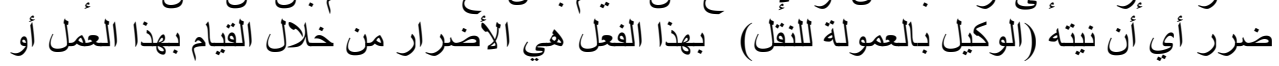
الامتناع عنه.

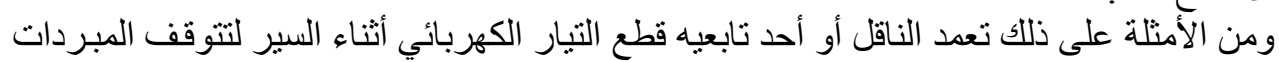

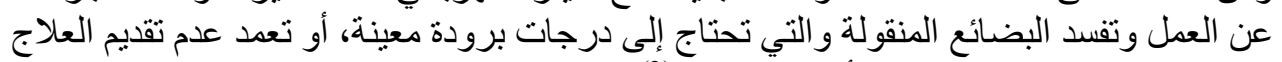

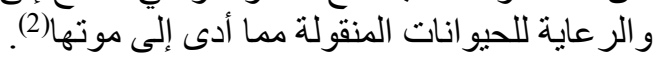

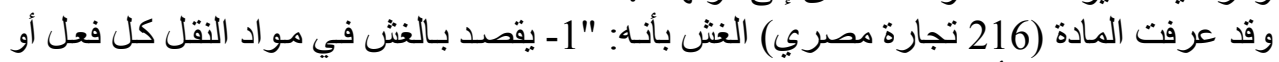

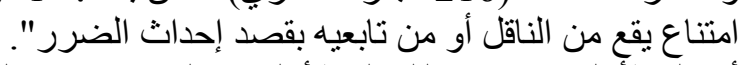

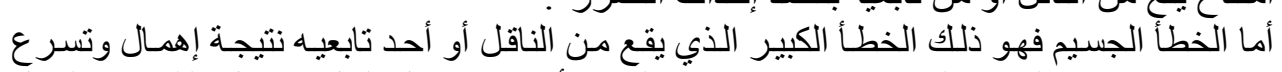

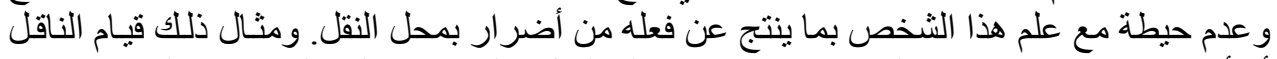

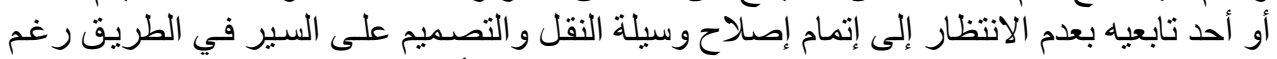

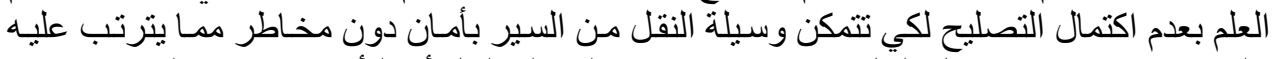

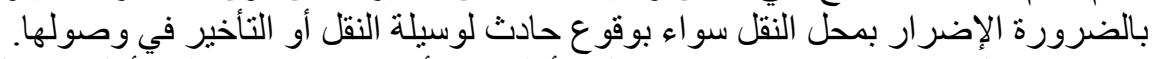

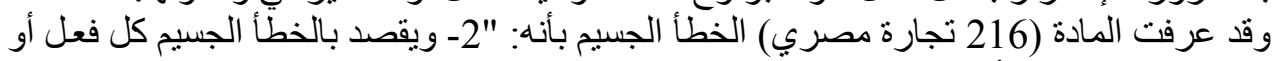

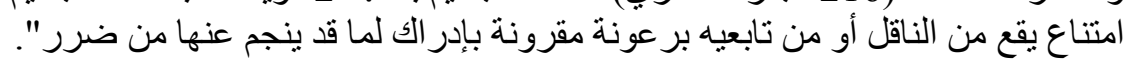

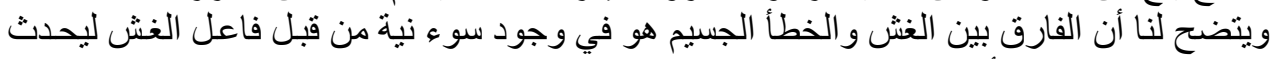

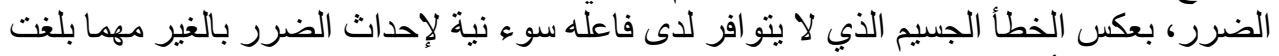

جسامة هذا الخطأ. كما يتضح لناوفق نص المادة (216 تجارة مصري) أن الضـرر الذي أصساب الأشياء محل النقل

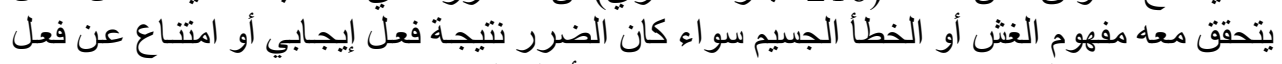

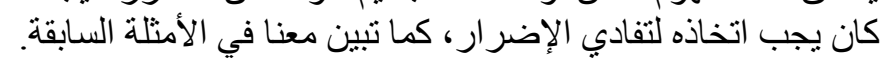

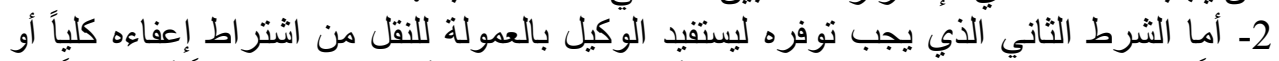

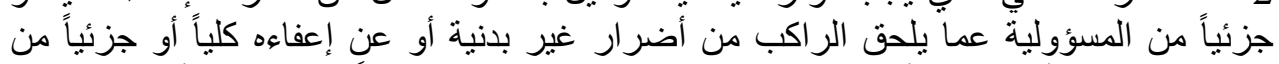

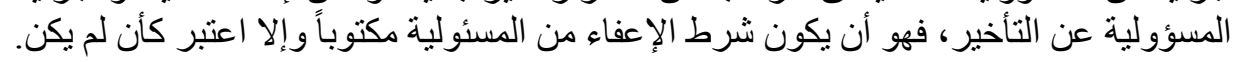

د. سميحة القليوبي: الوسيط في شرح قانون التجارة المصري، 2007، ص552. 


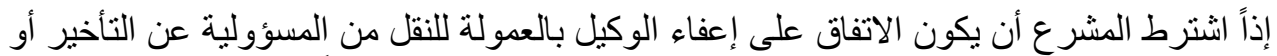

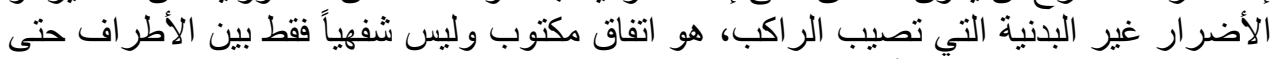

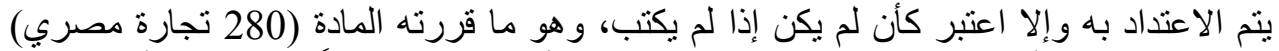

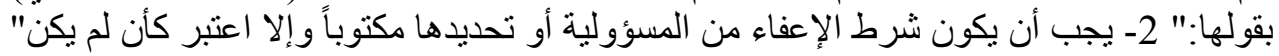

3- أما الشرط الثالث والأخير هو في حالة كون عقد الوكالة بالعمولة للنقل قد حرر على نماذج مطبو عة فيجب في هذه الحالة أن يكون شرط الإعفاء قد قد طبع بشكل واضح وبطريقة تجلب الانتباه

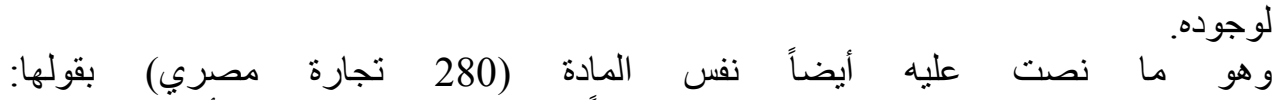

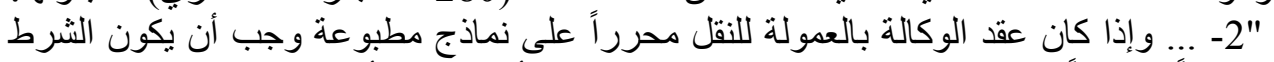

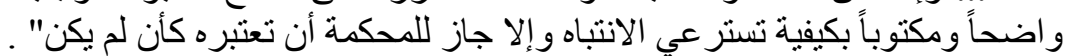

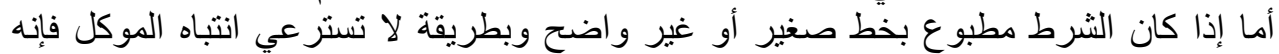

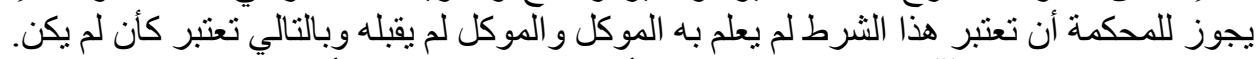

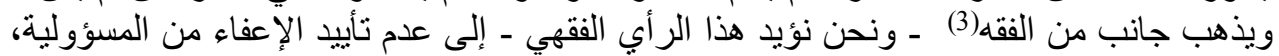

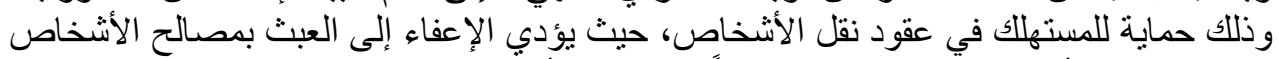

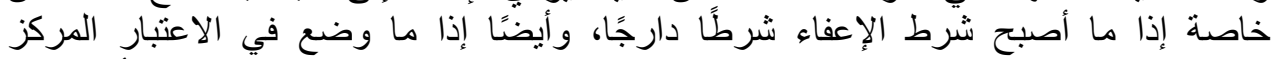

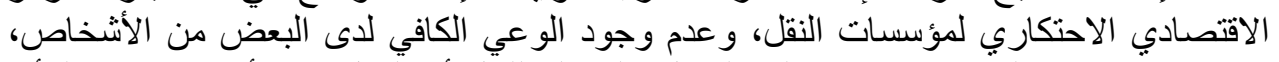

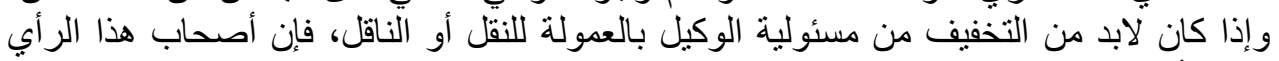

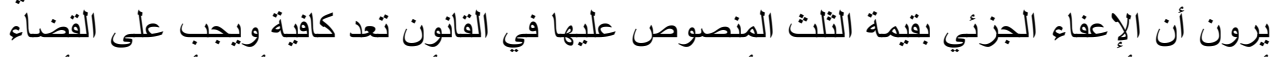

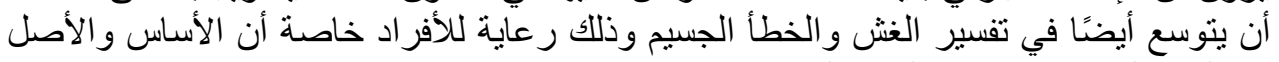

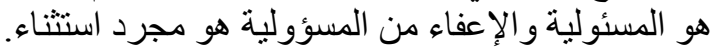

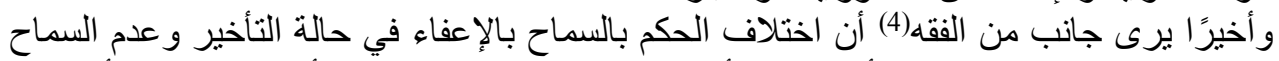

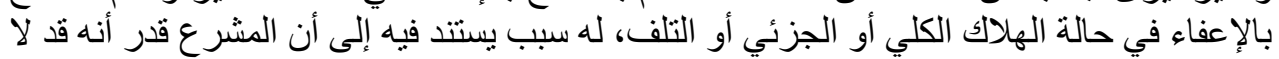

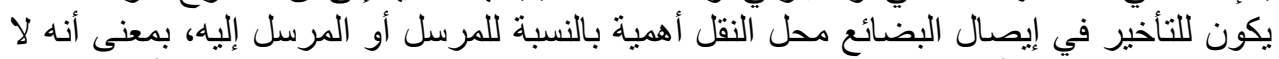

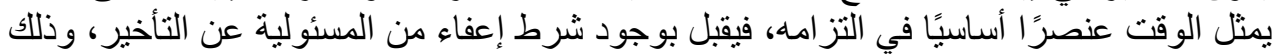

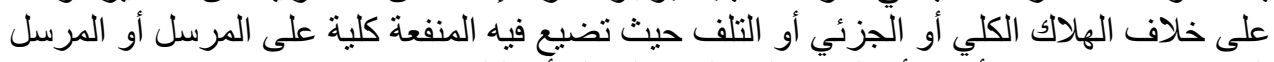

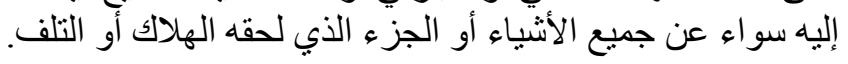

$$
\text { التحديد الأتفاقي للمسؤولية }
$$

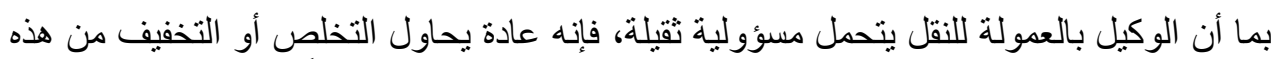

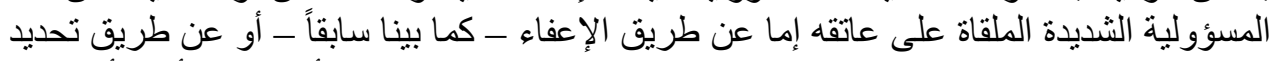

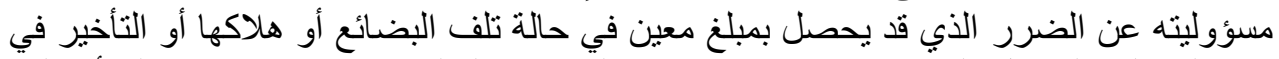

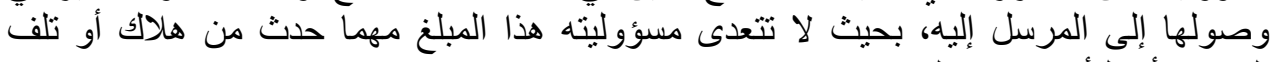
البضائع أو التأخير في تسليمها.

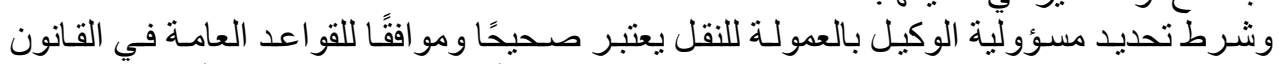
المدني المصري، حيث قضت المادة (223 مدني مصري) بأنه "يجوز للمتعاقدين المين أن يحددا مقدمًا

$$
\text { د. دمد الجوهري، مرجع سابق، ص358. }
$$

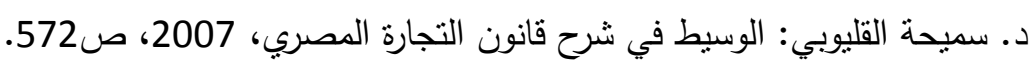


قيمة التعويض بـالنص عليها في العقد أو في اتفاق لاحق، وير اعى في هذه الحالة أحكام المو اد 215، 220

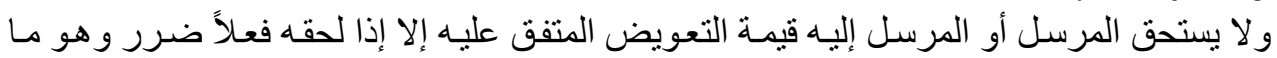

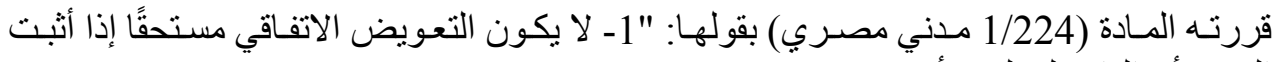

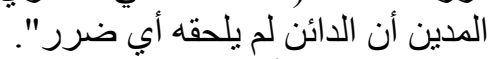
ويجوز للقاضي أن يخفض هذا التعويض إن إذا أنثبت المدين أن التقدير كان مبالغًا فيه إلى درجة كبيرة

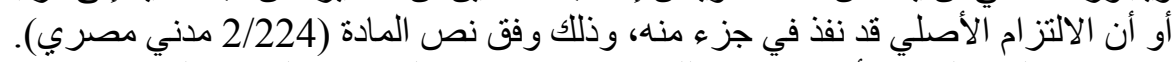

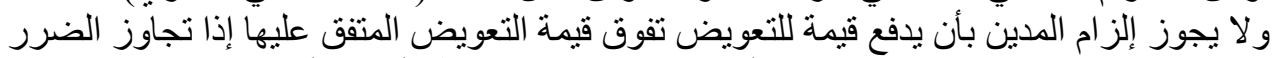

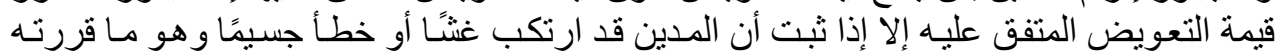

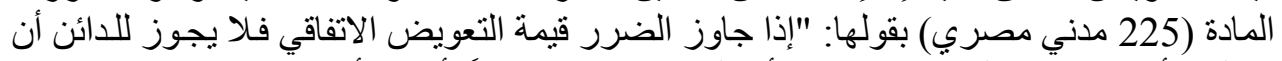

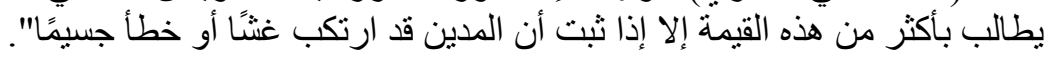

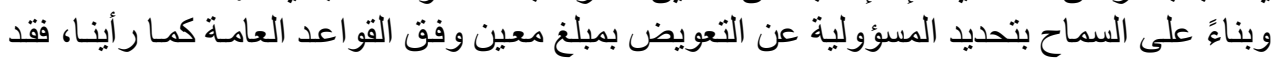

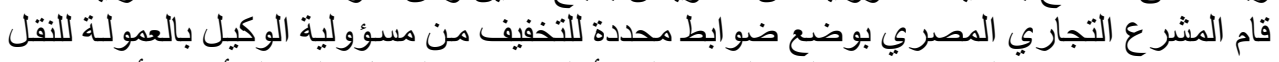

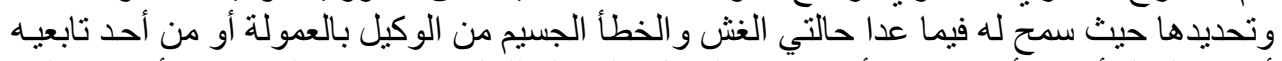

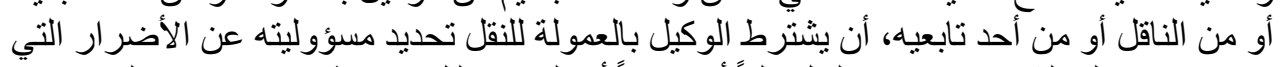

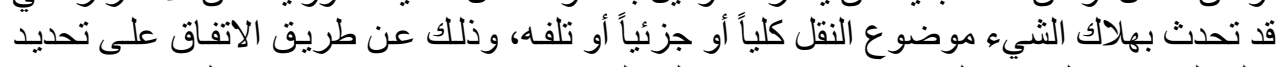

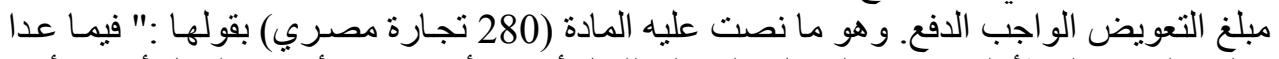

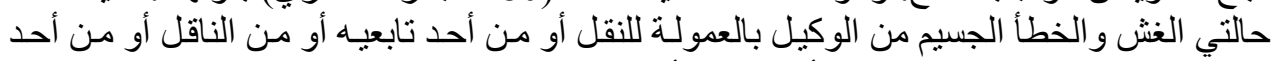

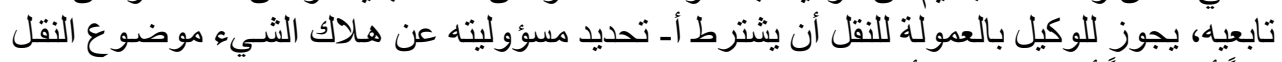

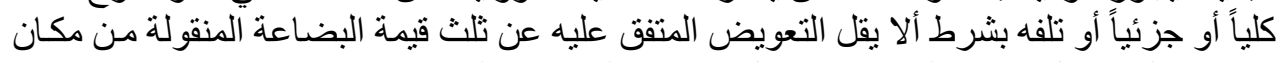

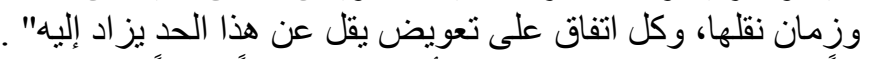

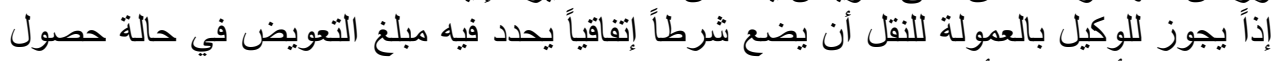

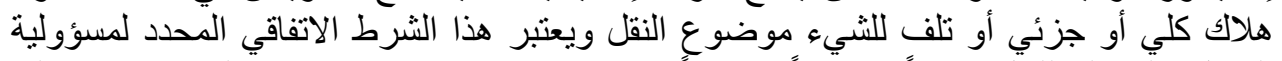

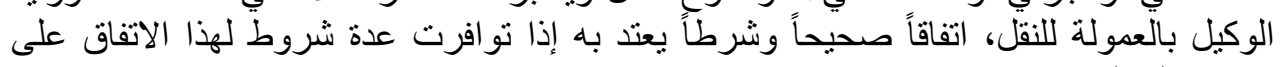
تحديد مبلغ التعوبض والتي:

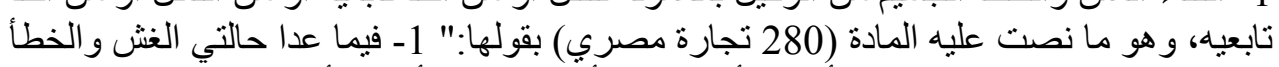

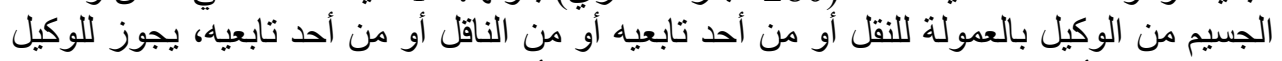

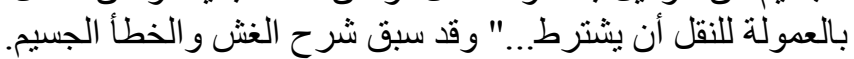

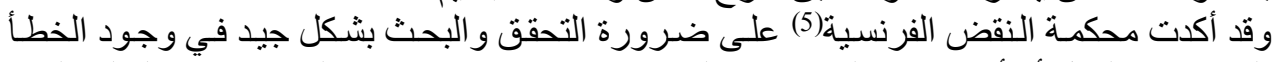

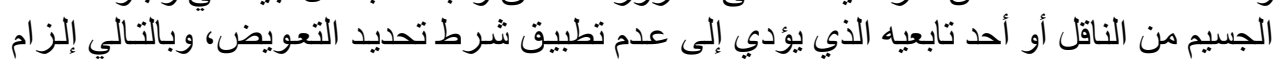

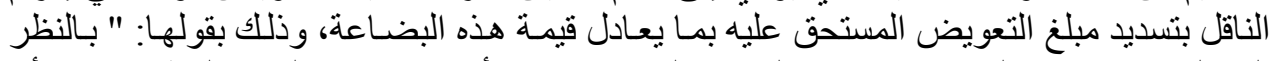

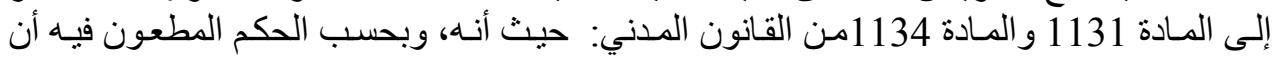

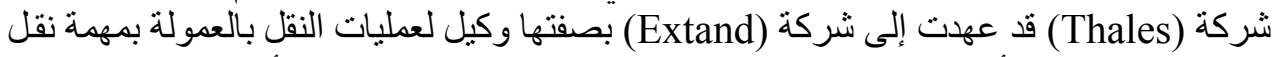

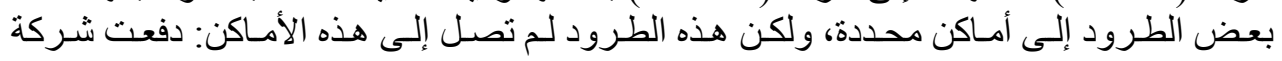

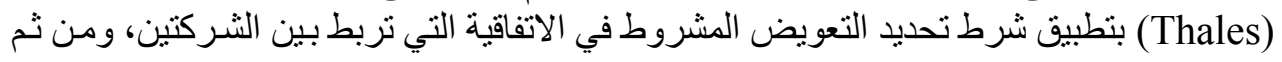

الحكم رقم 834 الصادر في2007/6/5 ، محكمة النقض الفرنسية ، الدائرة التجارية ،

الموقع الالكتروني: www.courdecassation.fr 


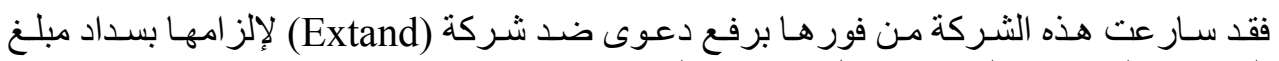

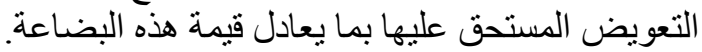

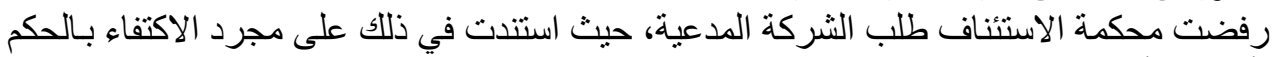

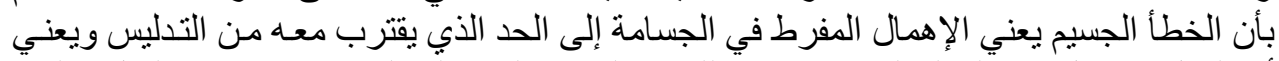

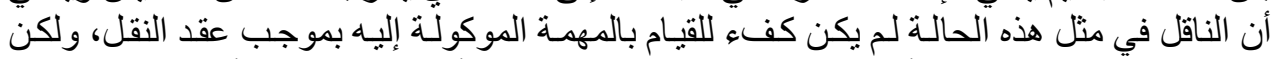

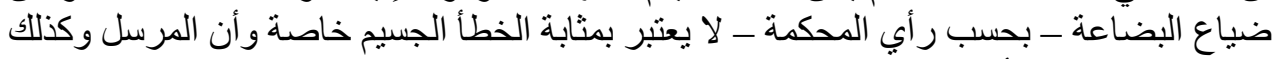

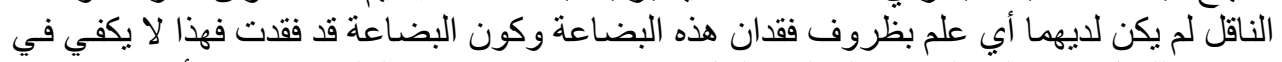

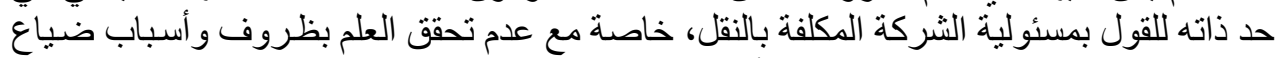

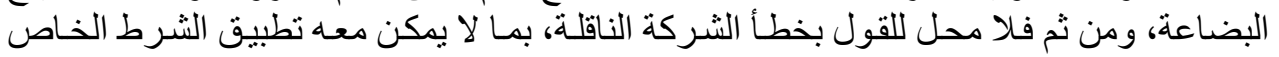

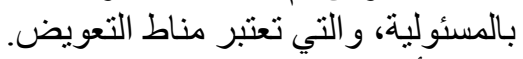

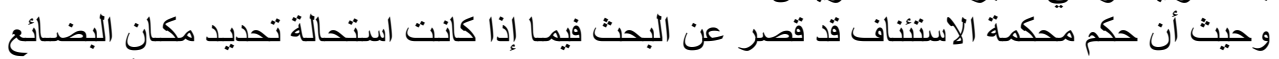

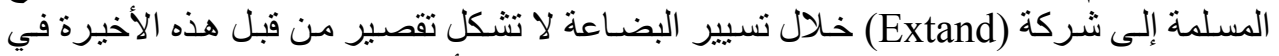

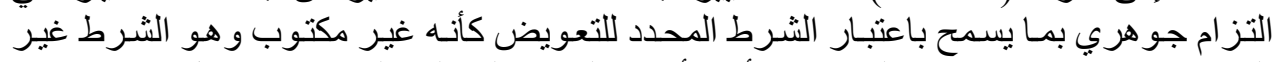

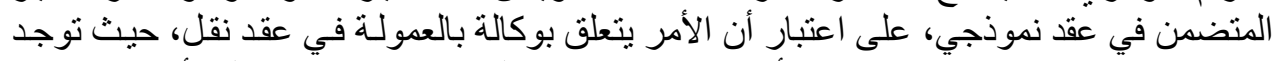

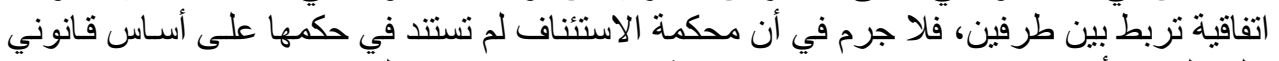

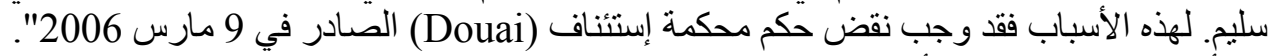

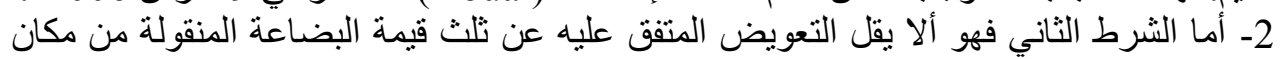

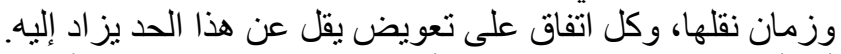

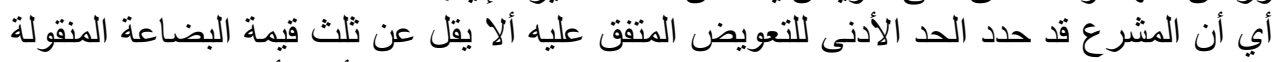

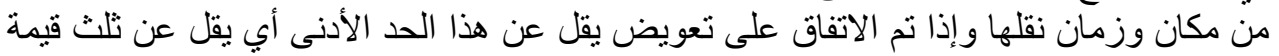

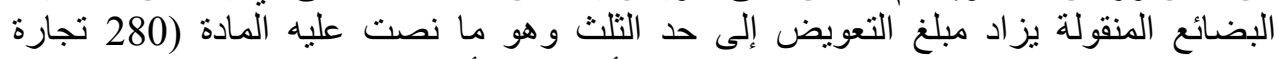

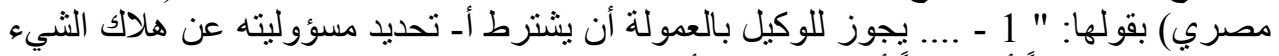

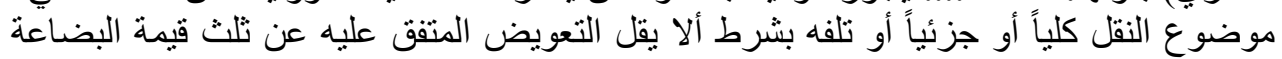

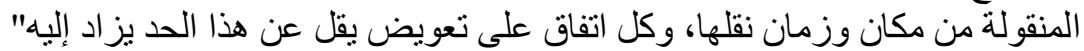

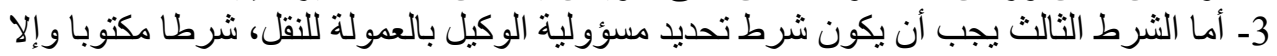

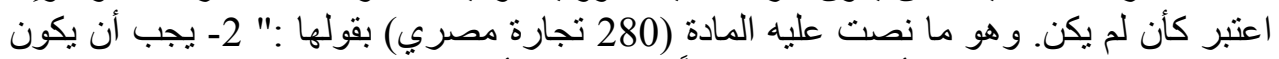

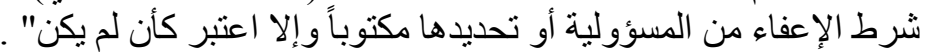

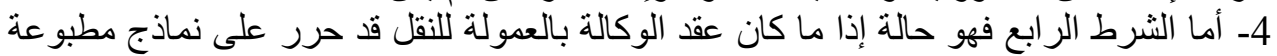

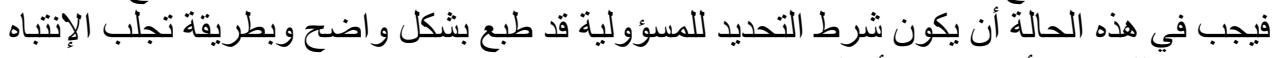

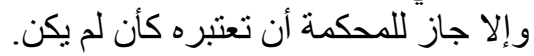

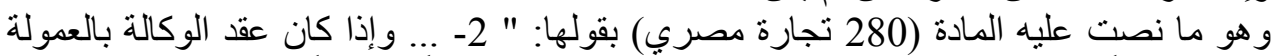

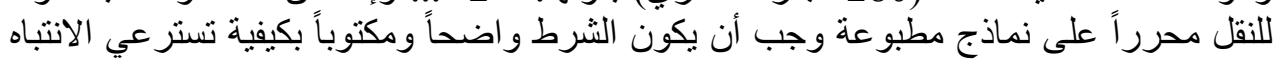

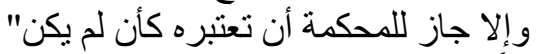

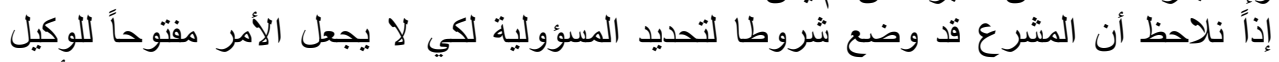

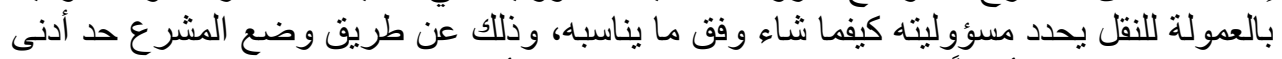

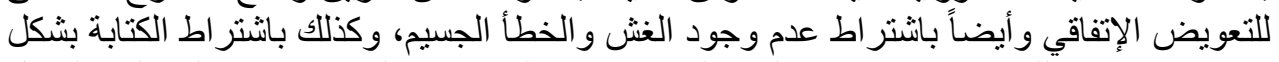

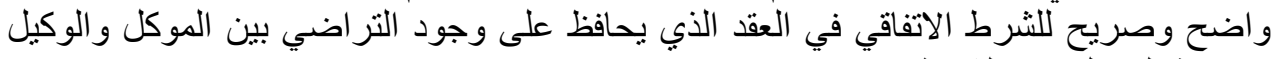
ومعرفة الموكل بهذا الثرط. 


\section{الحدود القانونية للثستئولية}

تمهيد و تقسيح :

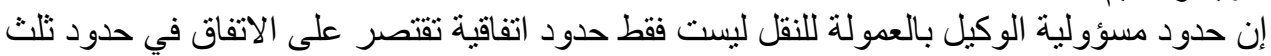

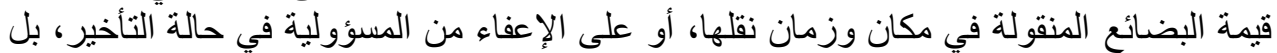

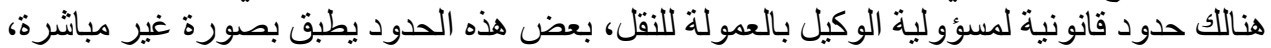

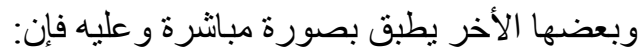

$$
\begin{aligned}
& \text { المطلب الاول }
\end{aligned}
$$

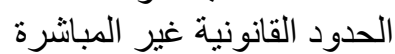

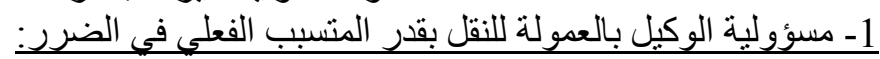

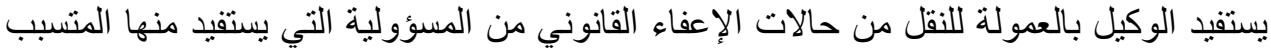

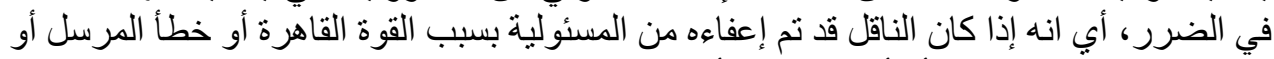

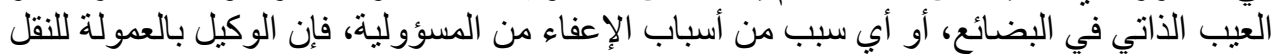

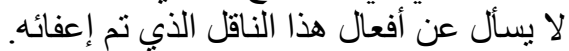

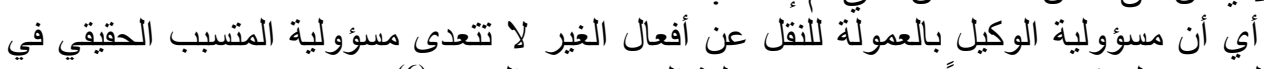

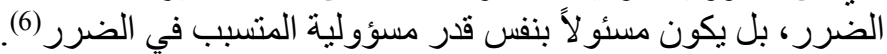

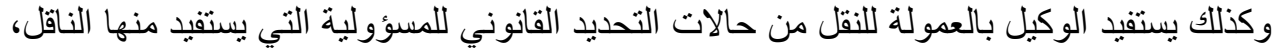

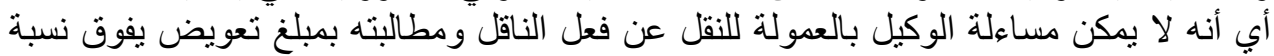

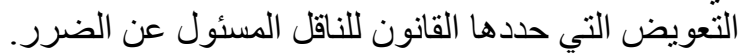

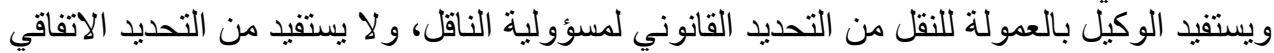

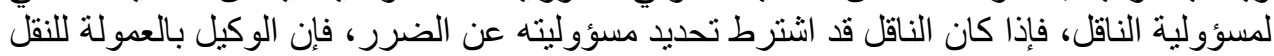

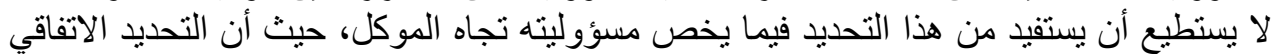

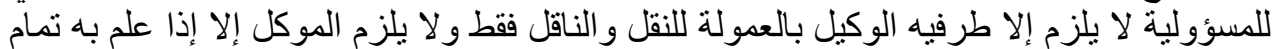

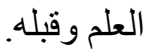
أما الوكيل بالعمولة للنقل فيستفيد من حالات التحديد القانوني لمسؤولية الناقل، سواء بعلم الموكل أو

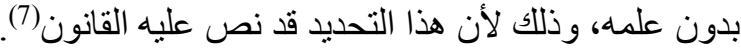

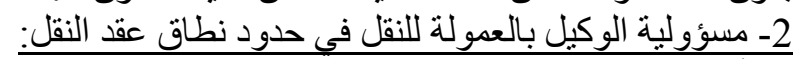

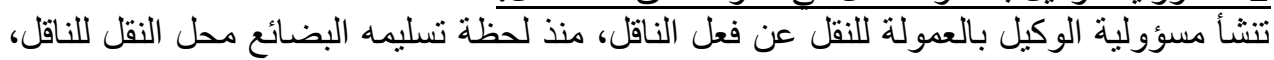

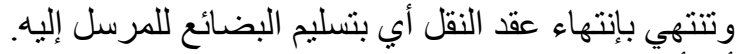

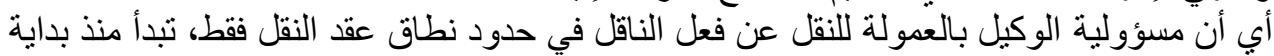

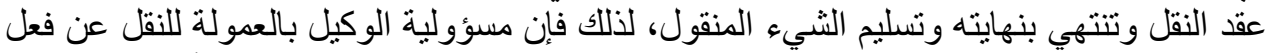

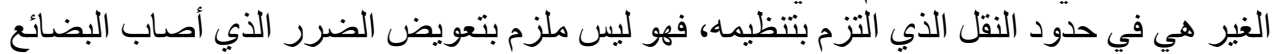

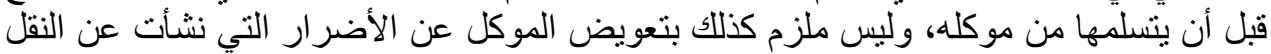

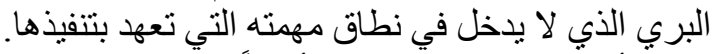

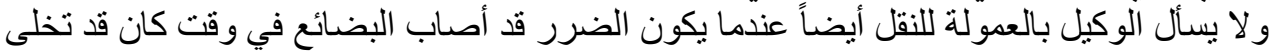

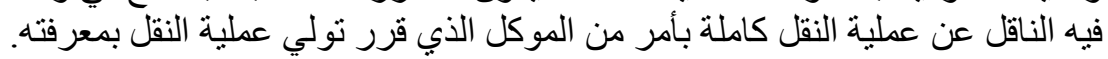

(1) د. سوزان علي حسن - مرجع سابق، ص 187.

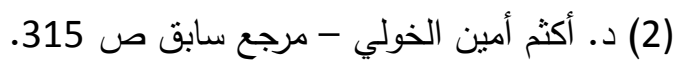




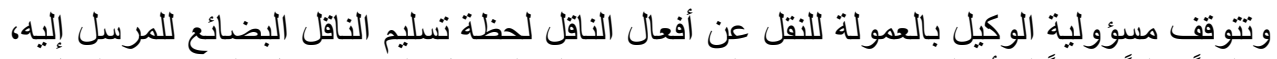

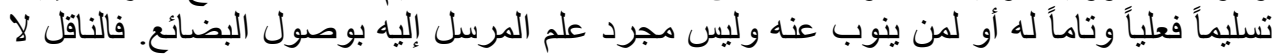

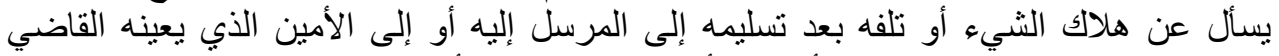

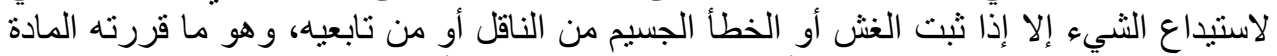

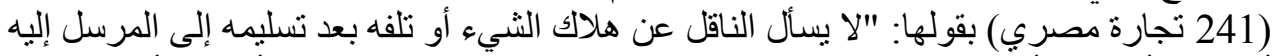

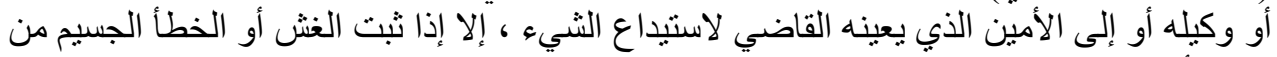

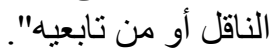

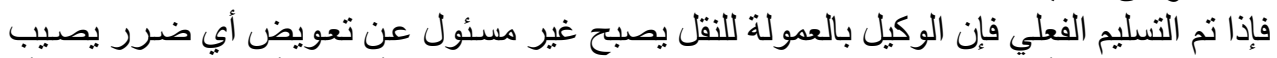

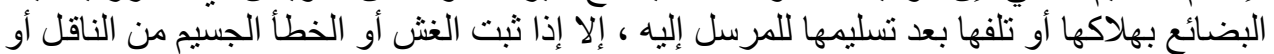

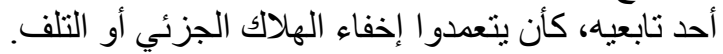

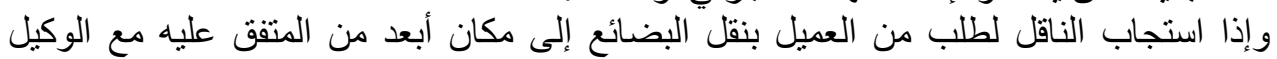

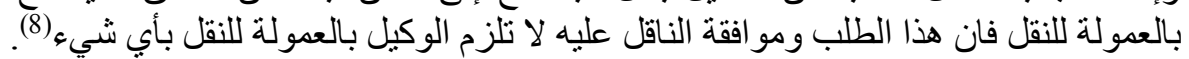

$$
\text { الحدود القانونية المباثرة الثاني }
$$

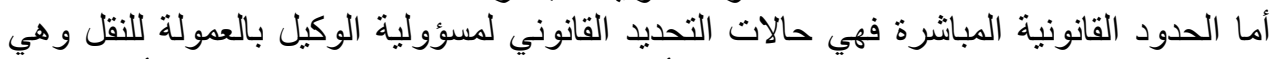

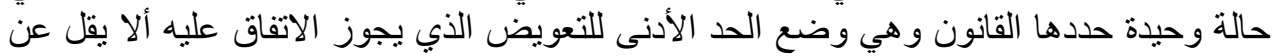

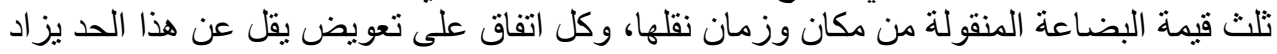

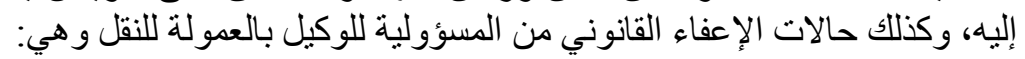

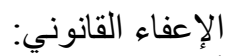

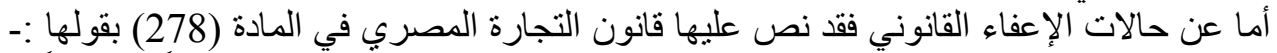

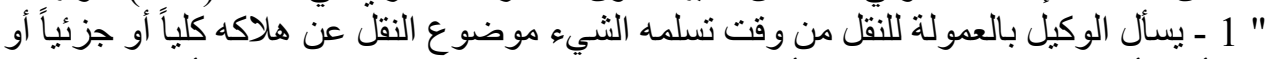

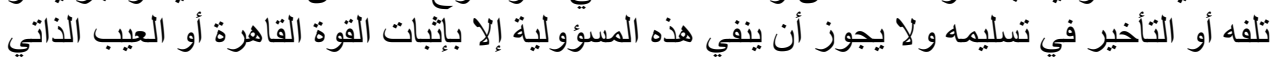

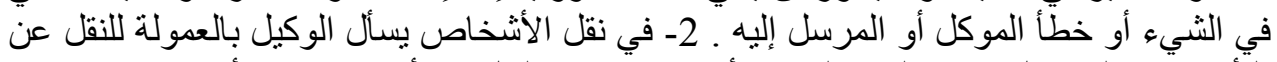

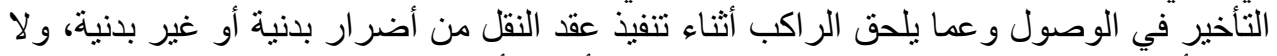

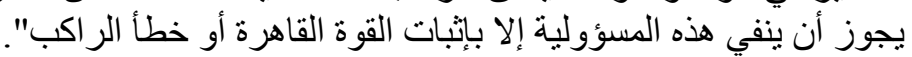

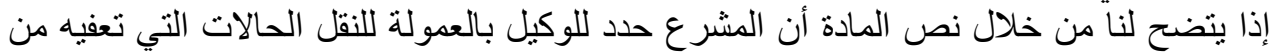

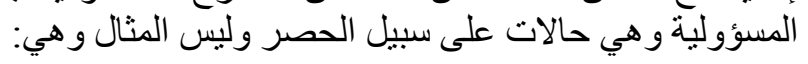

1أـ في عقد نقل الأشياء:

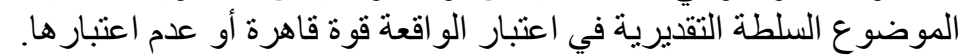

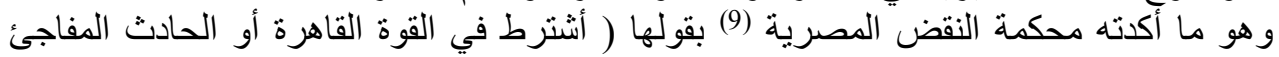

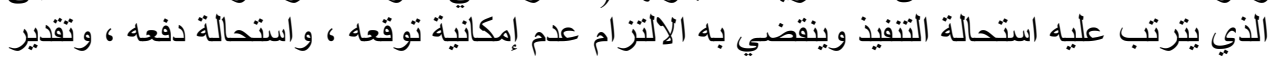

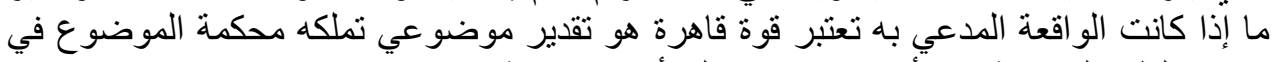

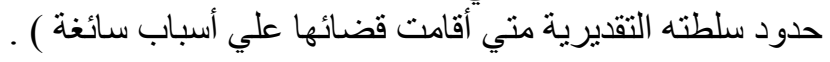

(1) د. سوزان علي حسن - مرجع سابق، ص 190.

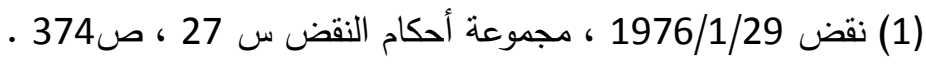


وكذللك بقولهـا(10) "2- القوة القاهرة بـالمعنى الوارد في المـادة 373 مـن القانون المـدني قد تكون

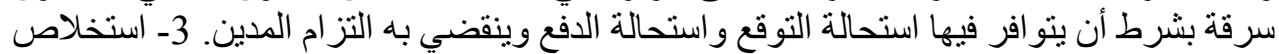

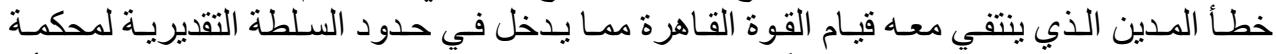

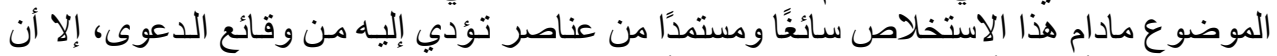

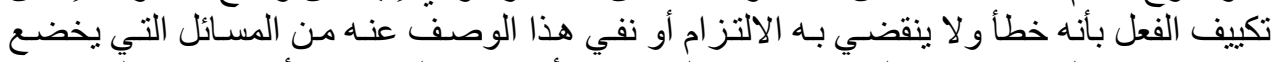

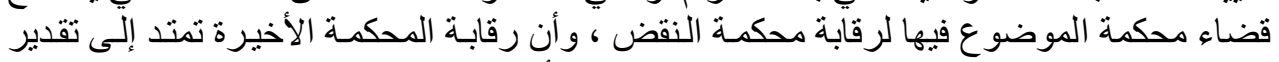

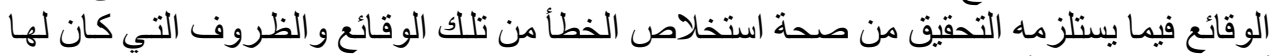

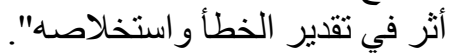

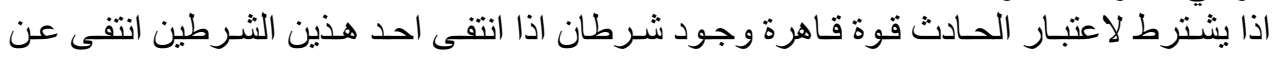

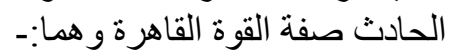

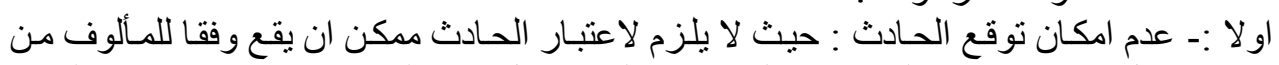

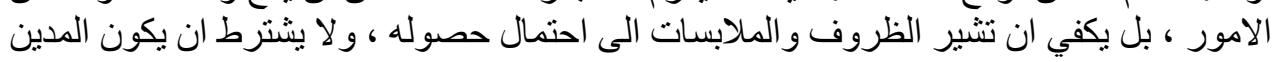

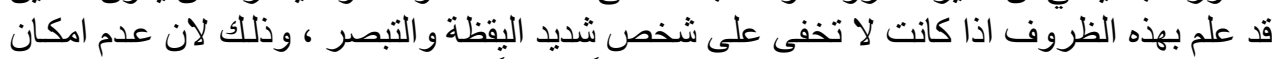

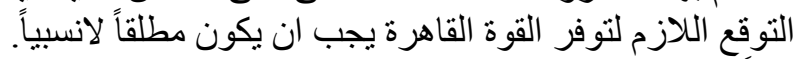

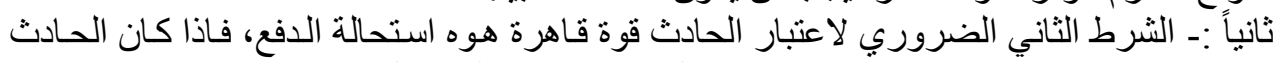

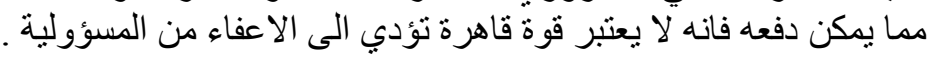

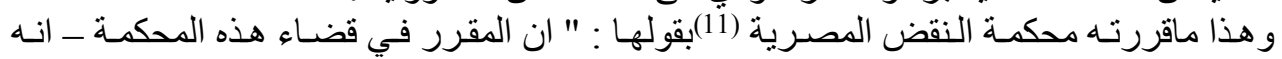

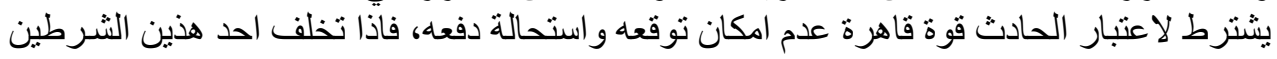

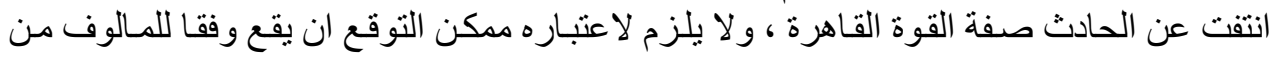

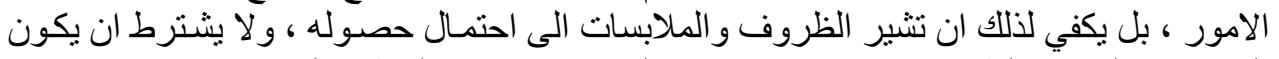

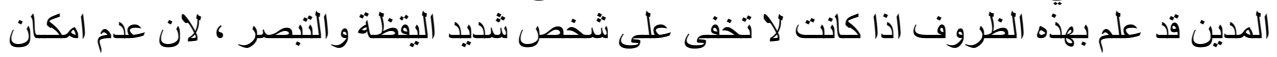

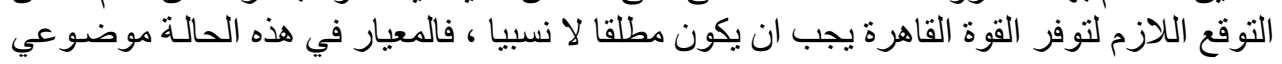

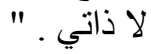

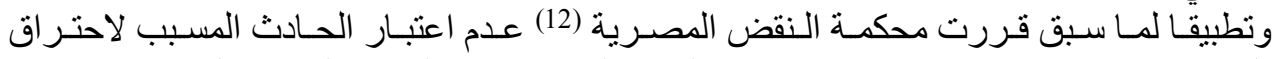

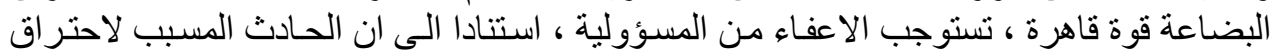

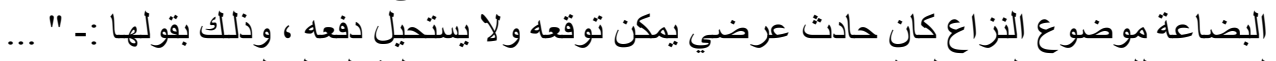

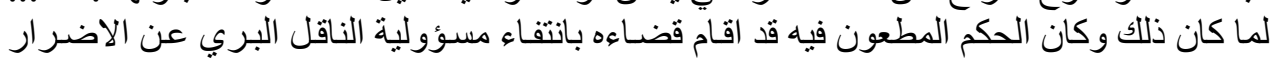

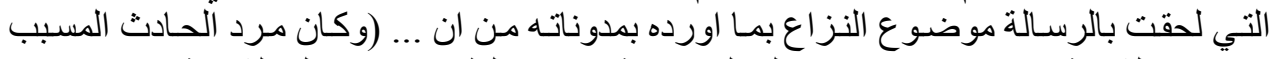

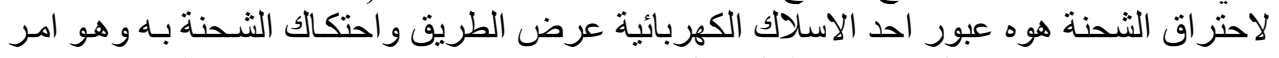

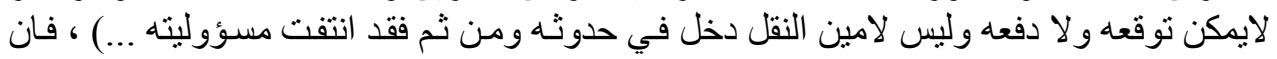

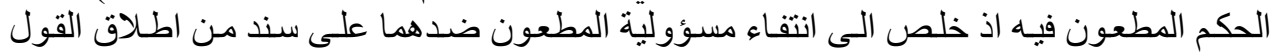

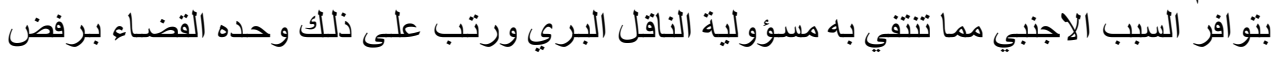

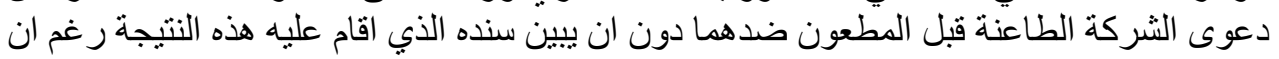

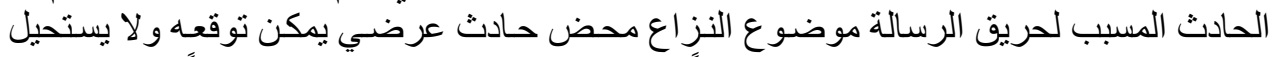

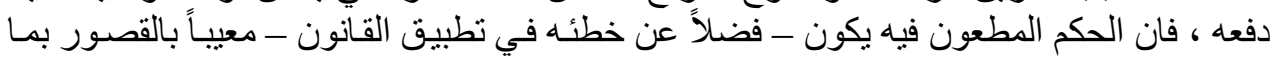




\section{Journal of Social Sciences (COES\&RJ-JSS), 10(1), pp.119-138}

ويعتبر من القوة القاهرة حوادث الحرب واستيلاء السلطة العامة على أداة النقل أو البضاعة، وقيود

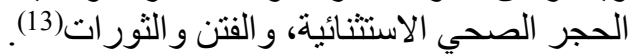

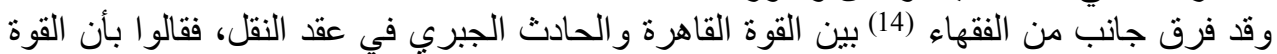

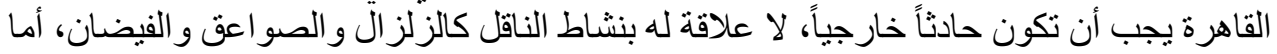

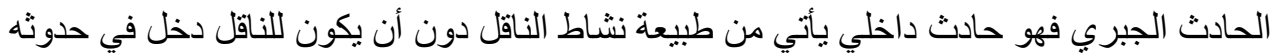

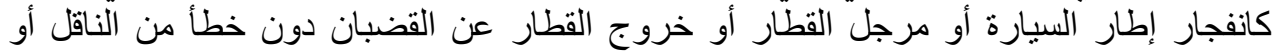

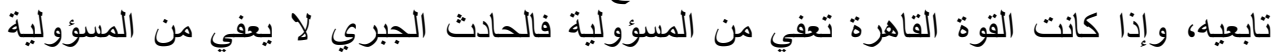

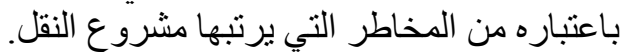

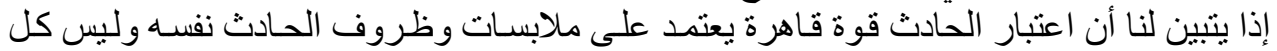

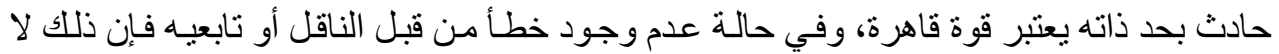

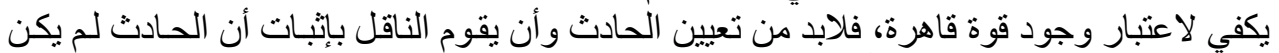

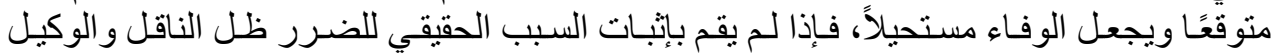
بالعمولة للنقل مسئو لان.

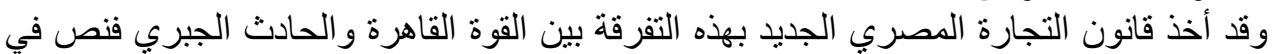

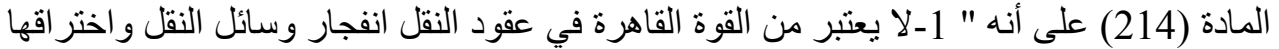

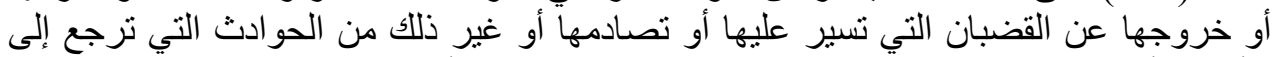

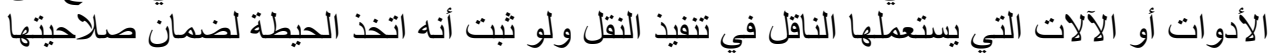

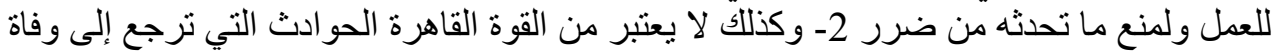

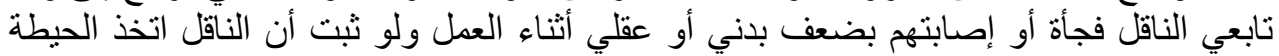

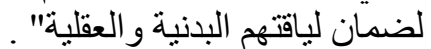

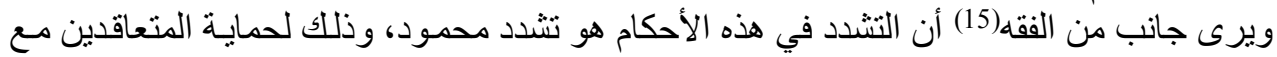

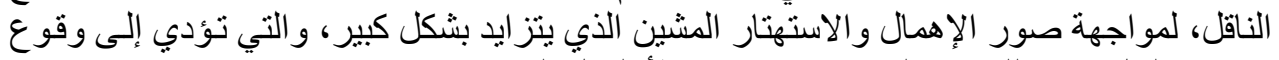

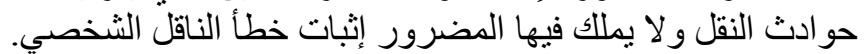

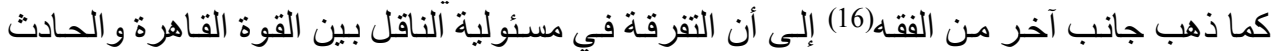

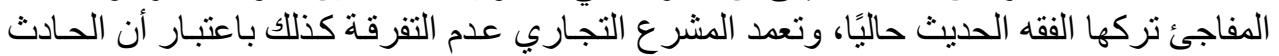

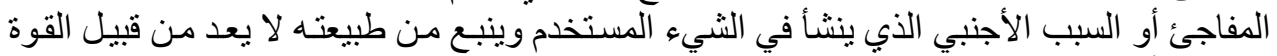

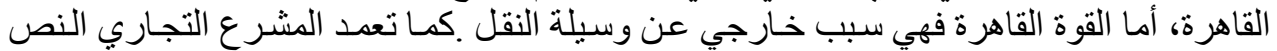

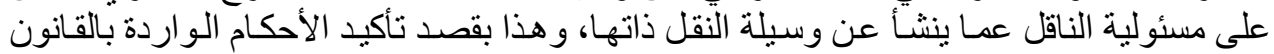

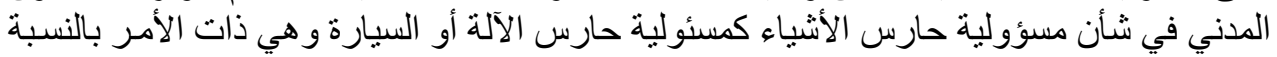
لمسؤولية حارس وسيلة النقل. 2- العيب الذاتي في الثيء حارسئ.

$$
\text { (1) د. علي البارودي - مرجع سابق، ص } 184 .
$$

(2) د. مصطفى طه- مرجع سابق، ص 184 ، د د ـ محمود مختار بريري - ثانون المعاملات

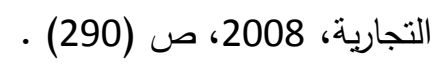

(15) د. سميحة القليوبي: الوسيط في شرح قانون التجارة المصري، 2007، صنانداند، د. د. محمود

$$
\text { مختار بريري، قانون المعاملات التجارية، 2008، ص291. }
$$

(16) د. سميحة القليوبي: الوسيط في شرح قانون التجارة المصري، 2007، ص530. 


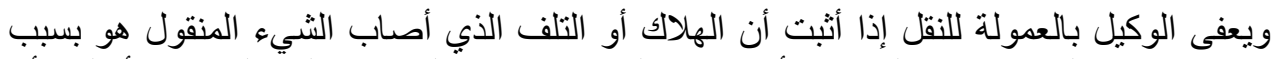

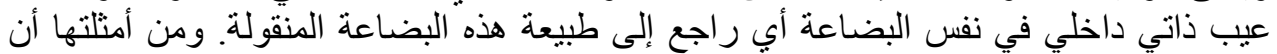

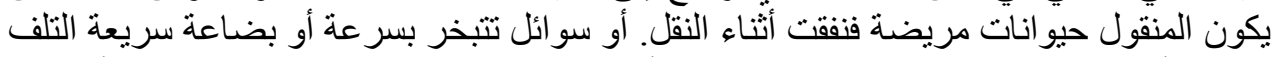
كبعض أنواع الفو اكه و الخضروات لكن لكن بشرط أن يكون تلف هذه البضاعة ليس بسبب التبر التأخر في النقل. و غالبًا ما يكون العيب الذاتي للبضاعة مرتبطًا بسوء التغليف أو التعبئة والتي هي من اختصساص

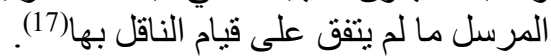

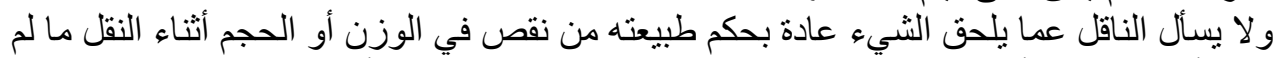

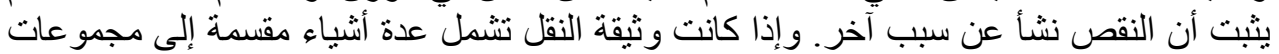

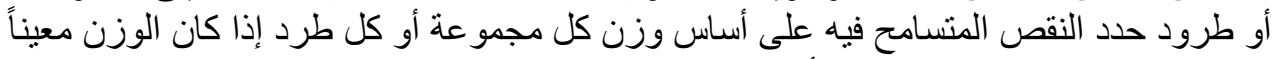

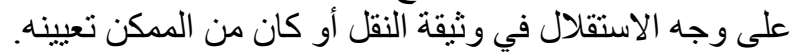

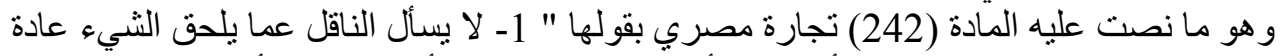

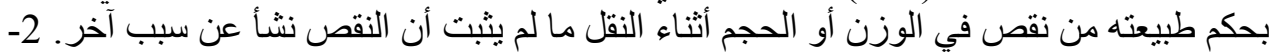

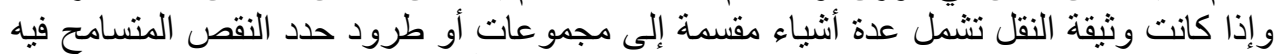

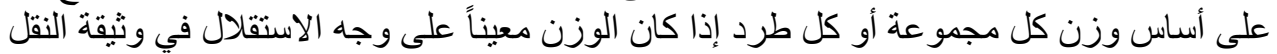

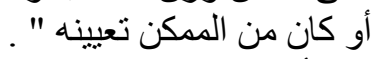

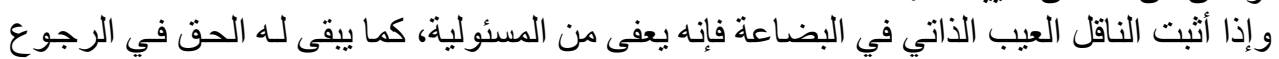

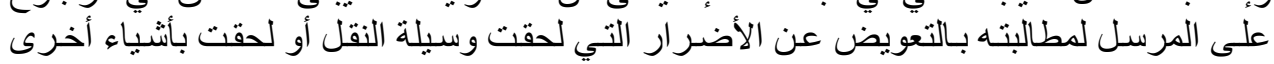

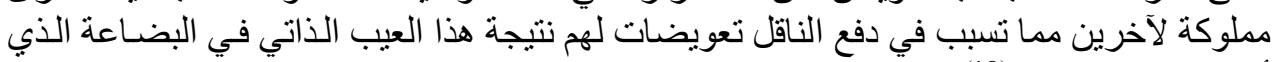
أدى لإحداث الضركة لاخرين معر (18).

أي فعل يصأ الموكل:

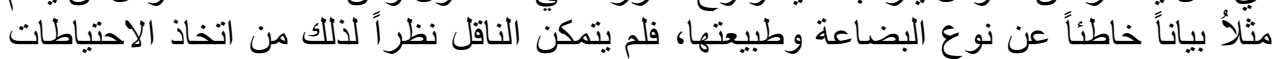

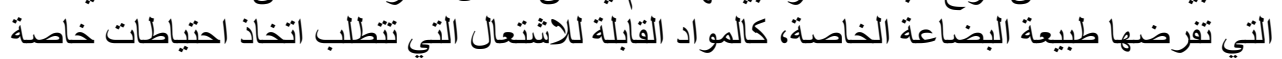

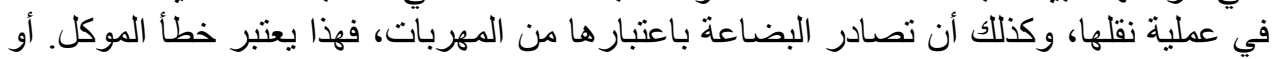

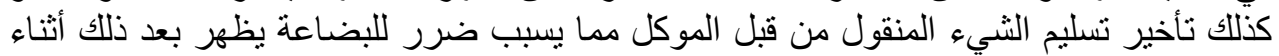

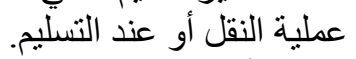
4- خطأ المرسل إليه: وهو أي فعل يصدر من المرسل إليه يترتب عليه وقوع ضرر للشيء المنيه المنقول كأن يرفض الاستلام

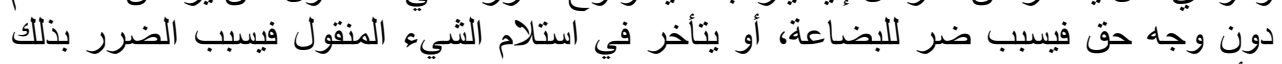
التأخير. وقد أكدت محكمة النقض المصرية(19) على هذه الأسباب التي تعفي الوكيل بالعمولة للنقل من

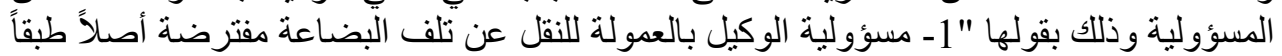

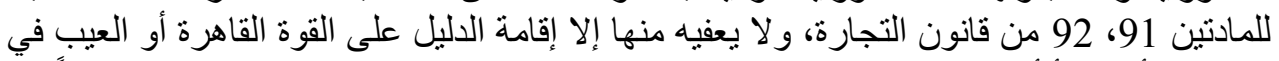

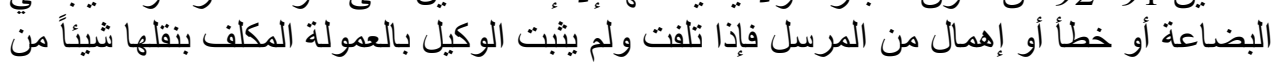

$$
\begin{aligned}
& \text { (17) د. سميحة القليوبي: الوسيط في شرح قانون التجارة المصري، 2007، ص568. }
\end{aligned}
$$

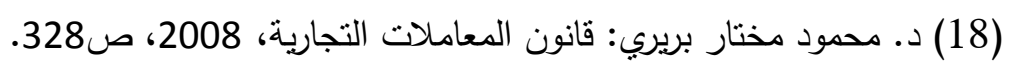

$$
\begin{aligned}
& \text { (3) طعن } 379 \text { سنة } 44 \text { ق ، جلسة 1956/6/28، س } 7 \text { ص ص } 767 .
\end{aligned}
$$


ذللك فإنه يتحمل مسؤولية التلف و لا يكون المرسل هو المكلف بإثبات خطأ الوكيل بالعمولة في هذه

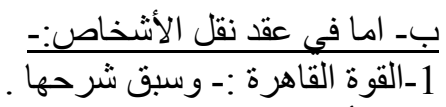

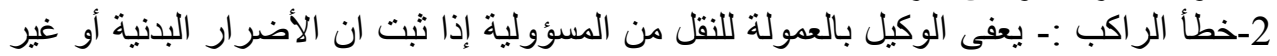

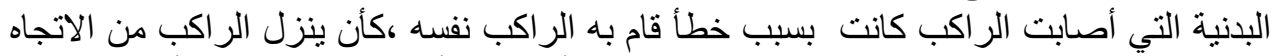

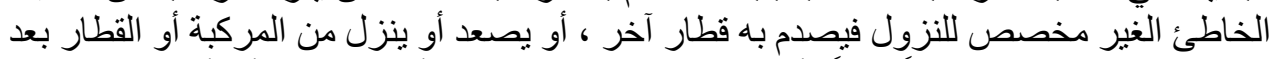

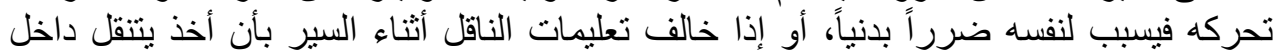

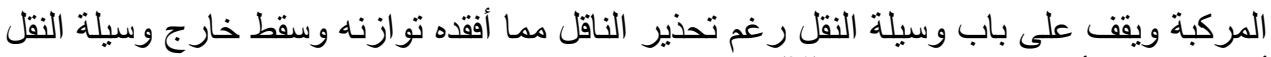
أو داخلها مما أدى إلى إصلى بابته بدنيًا (20). ويجب ان يكون خطأ الر اكب هو السبب الرئيسي و الوحيد لوقوع الضـر لـور للر اكب ليعفى الوكيل

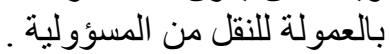

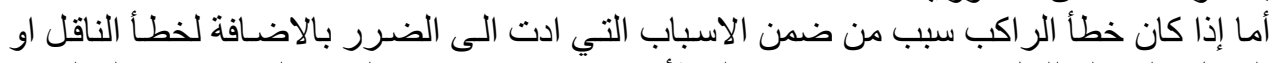

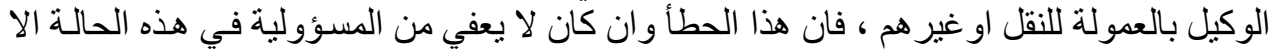

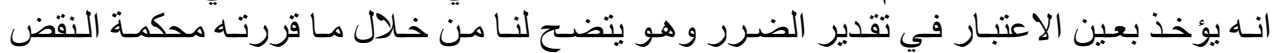

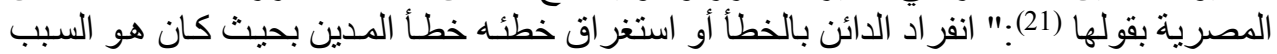

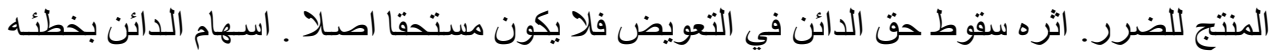

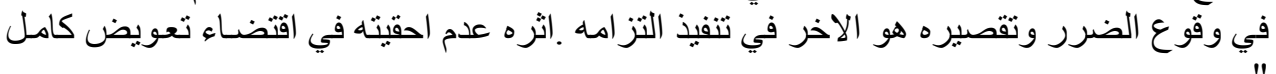

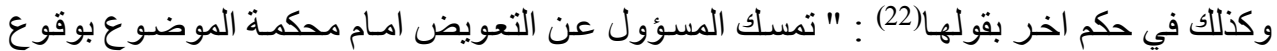

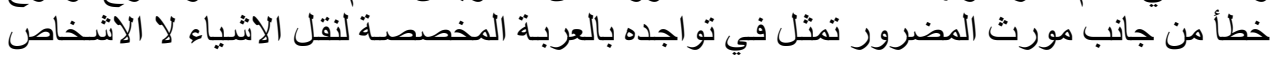

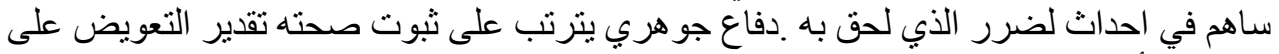

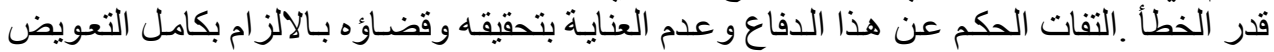

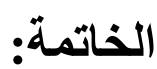

يتضح لنا من خلال هذه الدراسة الأهمية الكبيرة للوكالة بالعمولة للنقل في الحياة التَّجاريَّة، وما

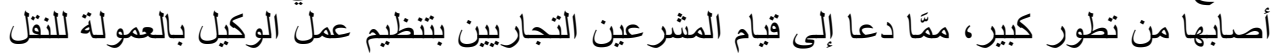

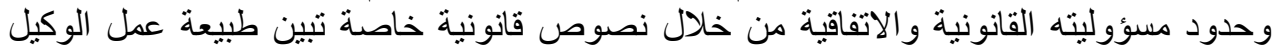

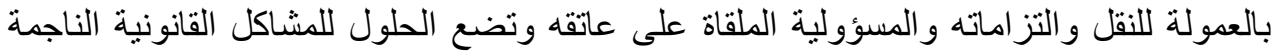
عن هذا العقد، وما هي العلاقات القانونية التي تفرضه التها طبيعة عقد الوكالة بالعمولة للنقل.

ولقد حاولنا من خلال هذه الدراسة أن نبين التَّفاصيل الخاصَّة بمسؤولية الوكيل بالعمولة للنقل

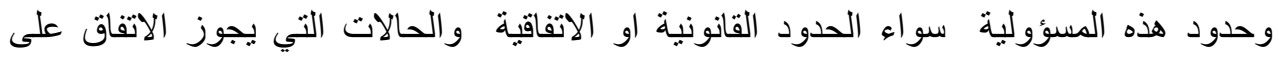

(20) د. سميحة القليوبي: الوسيط في شرح قانون التجارة المصري، 2007، ص594. (21) طعون ارقام 1859 ،2444، 2447، لسنة 70 ق ، جلسة 12/ 12/ 12 / 2001 مجموعة

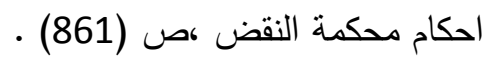

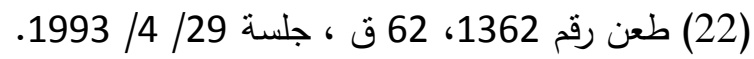




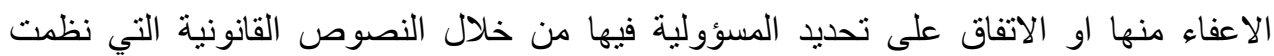

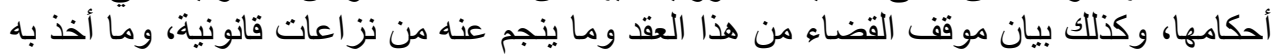
العرف التجاري فيما يتعلق بطبيعة هذا المهنة الخاصة.

ونظراً لتعدد الموضوعات المرتبطة والمتفرعة من عقد الوكالة بالعمولة للنقل فقد حاولنا-بقدر

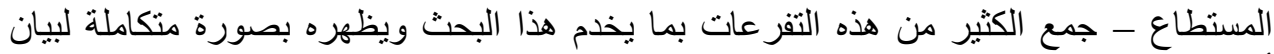

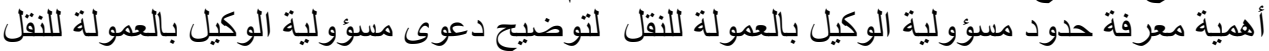

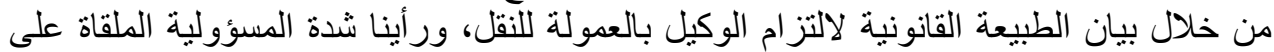

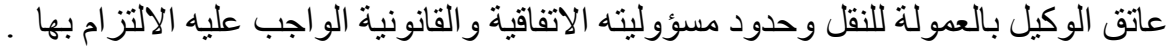

: التنتائجج

1. يتضح لنا من خلال هذه الدر اسة ان مسؤولية الوكيل بالعمولة للنقل هي مسؤولية محددة و شديدة

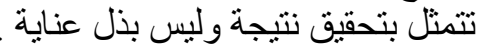

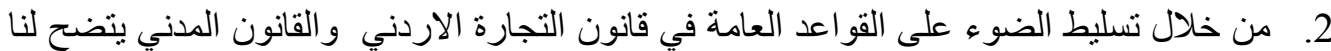

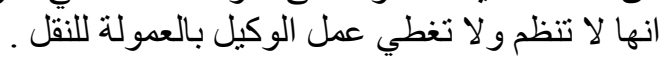
3. من خلال هذه الدراسة نجد ان الاعفاء من المسؤولية في القانون المصري لا لا يحمي المستهلك في

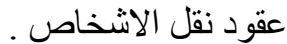

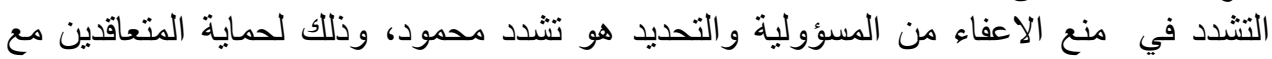

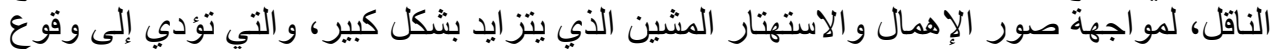

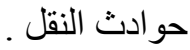

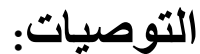
ونرجو ا في نهاية هذا البحث من مشر عنا الأردني أن بنظم الوكالة بالعمولة للنقل في فرع مستقل

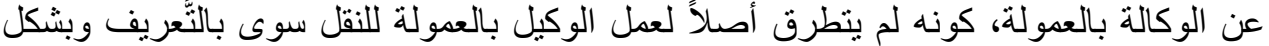

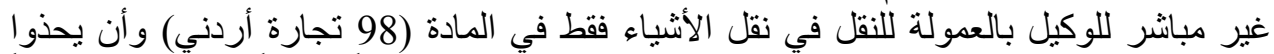

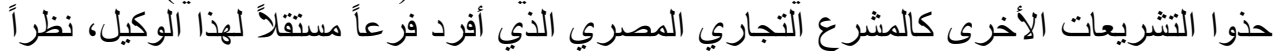

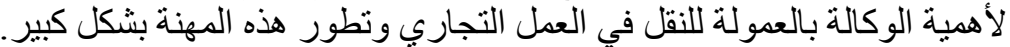

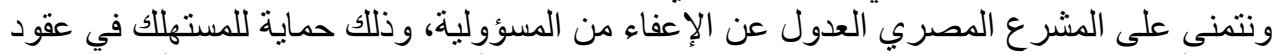

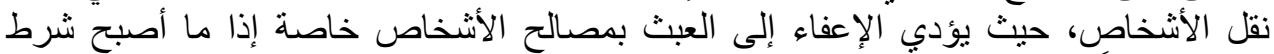

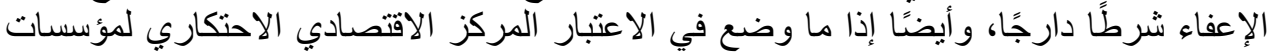

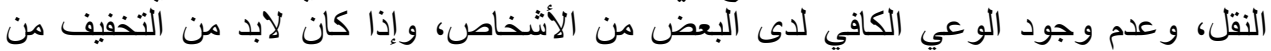

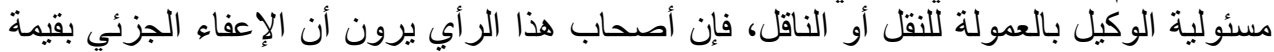

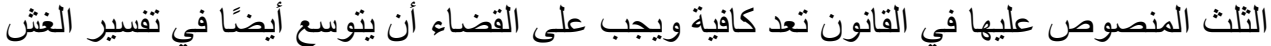

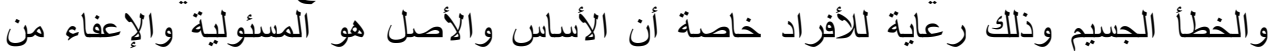
المسؤولية هو مجرد استثناء.

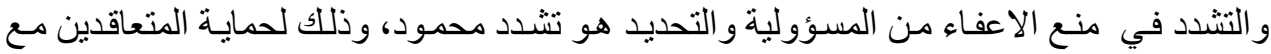

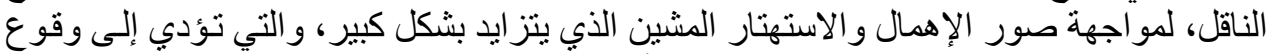

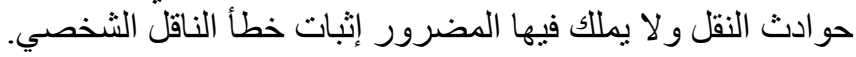

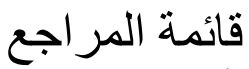
1. أكرم باملكي، القانون التجاري (دراسة مقارنة) الجزء الأول، دار الثقافة للنشر و التوزيع، عمان،

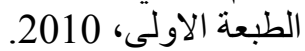




\section{Journal of Social Sciences (COES\&RJ-JSS), 10(1), pp.119-138}

2. سميحة القليوبي، الوسيط في شرح قانون التجارة المصري (الجزء الثاني) دار النهضة العربية،

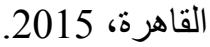
3. عبد الرزاق السنهوري، الوسيط في شرح القانون المدني، 1958.

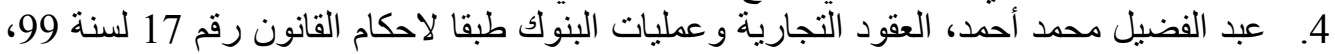

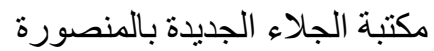
5. عزيز العكيلي، الوسيط في شرح القانون التجاري (الاعمال التجارية، العقود التجارية، التجار، المتجر )، دار العكئ

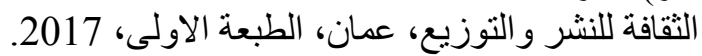

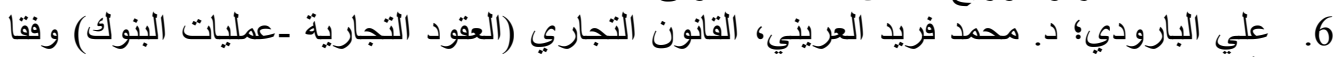
لأحكام قانون

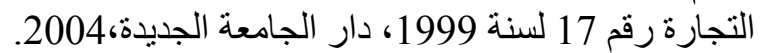
7.

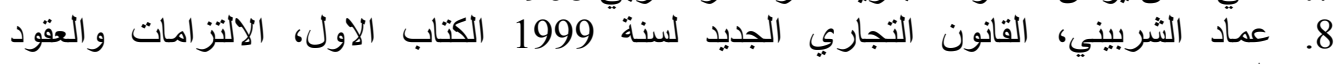

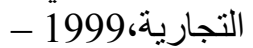
.2000

9. محسن شفيق، الوسيط في القانون التجاري المصري (الجزء الثاني)، مطبعة اتحاد الجامعات،

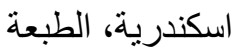

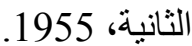

10. مصطفى كمال طه، العقود التجارية، دار الفكر الجامعي، اسكندرية، 2005 التوانية

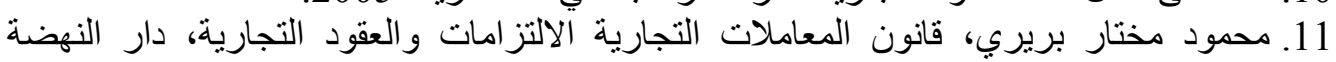

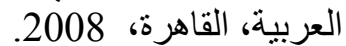
12. سوزان علي حسن، الإطار القانوني للوكالة بالعمولة للنقل وفقا لقانون التجارة رقم 17 لسنة

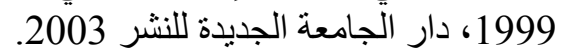
13. حمد الله محمد حمد الله، الوكيل بالعمولة للنقل (در اسة مقارنة بين القانون المصري و الفرنسي)، دار النهضة العربية، 1992. 192. 14. سوزان علي حسن، التنظيم القانوني لمسؤولية متعهد النقل متعدد الوسائط، منشاة المعارف بالإسكندرية، 2004

\section{أبحاث ومقالات:}

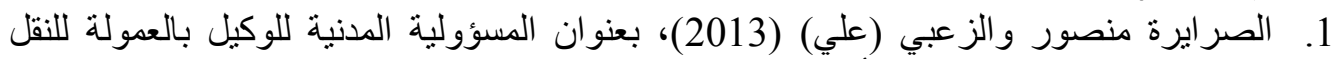

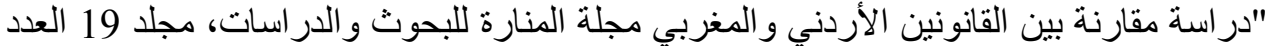

2. الوكالة بالعمولة في القانون الكويتي، د. سميحة القليوبي، مجلة القانون والاقتصاد سنة 1975

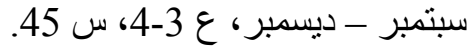
3. معيار التفرقة بين الوكالة بالعمولة والوكالة العادية د. دالعلي البارودي مجلة القانون الاقتصاد السنة

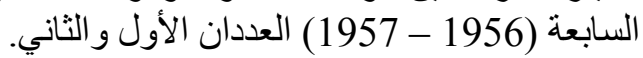
4. الوكلاء التجاريون د. سعيد يحيى مجلة القانون والاقتصاد سبتمبر - ديسمبر 1977. 


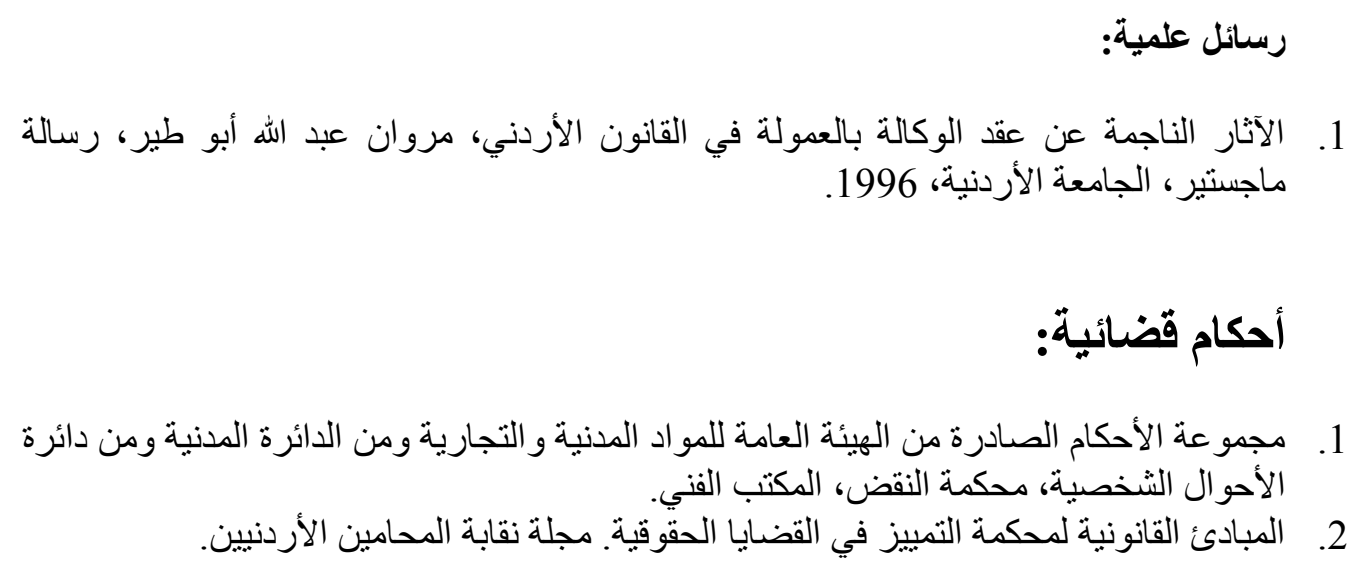

\section{References}

Abdelfadhil Mohammad Ahmad, Commercial Contracts and bank processes according to Law no. 17 of 1999, Al-Jala' Al-Jadida Library in AlMansoura.

Abdelrazzaq Al-Sanhoori, the Mediator in Explaining the Civil Law, 1958.

Akram Yamalki, Commercial Law (Comparative Study), Part one, Dar Al-Thaqafa Publication and Distribution, Amman, first edition, 2010.

Ali Al-Baroodi; Dr. Mohammad Fareed Al-Oraini, Commercial Law (Commercial Contracts - Bank Processes) According to Law no. 17 of 1999, A1Jamia’ Al-Jadida Library, 2004.

Ali Hasan Younis, Commercial Contracts, Dar Al-Fikr Al-Arabi, 1968.

Aziz Al-Oqaily, the Mediator in Explaining the Commercial Law (Business, Commercial Contracts, Traders, Shop), Dar Al-Thaqafa Publication and Distribution, Amman, first edition, 2017.

Emad Al-Sharbini, the New Commercial Law of 1999, first book, Commercial Liabilities and Contracts, 1999-2000.

Hamadallah Mohammad Hamadallah, Transport Commission Agent (Comparative study between the Egyptian and French law), Dar Al-Nahdha AlArabiya, 1992.

Mahmoud Mukhtar Bariri, Commercial Transactions Law: Commercial Liabilities and Contracts, Dar Al-Nahdha Al-Arabiya, Cairo, 2008. 


\section{Journal of Social Sciences (COES\&RJ-JSS), 10(1), pp.119-138}

Muhsen Shafeeq, the Mediator in Explaining the Egyptian Commercial Law (part two), Etihad Al-Jami'at Press, Alexandria, Second edition, 1955.

Mustafa Kamal Taha, Commercial Contracts, Dar Al-Fikr Al-Jamie', Alexandria, 2005.

Sameeha Al-Qayloubi, the Mediator in Explaining the Egyptian Commercial Law (part two), Dar Al-Nahda Al-Arabia, Cairo, 2015.

Suzan Ali Hasan, the Legal Context of Transport Commission Agent according to the Trade Law No. 17 of 1999, Dar Al-Jamia' Al-Jadida, 2003.

Suzan Ali Hasan, the Legal Regulation of the Liability of Multi-Modal Transportation Agent, Al-Ma'aref establishment in Alexandria, 2004.

Researches and Articles:

Al-Sarairah Mansour and Al-Zo'bi (Ali) (2013) titled" The Civil Liability of Transport Commission Agent" Comparative Study Between Jordanian and Moroccan laws, Al-Manara Researches and Studies Journal, Vol. 19, 1 edition.

Commercial agents, Dr. Said Yahya, Law and Economy Journal, Sep.Dec 1997.

Transport Commission Agent in the Kuwaiti Law, Dr. Sameeha AlQalyoubi, Law and Economy Journal of 1975 Sep.-Dec., 3-4 Ed., P.45.

The Differentiation Standard between Normal Agency and Commission Agency, Dr. Ali Al-Baroodi, Law and Economy Journal, seventh year (19561957), first and second edition.

Theses

Impacts of Transport Commission Agent in the Jordanian Law, Marwan Abdallah Abu Tair, Mater thesis, University of Jordan, 1996.

Verdicts:

A collection of verdicts issued by the General Body of Civil and Commercial Articles, the Civil Department, The Civil Status Department, Cassation Court, and The Technical Office.

The Legal Principles of Supreme Court in Legal Cases, the Jordanian Bar Association Journal. 